Iibrary, N.W. BIdg
OCT 5 196?

NBS MONOGRAPH 54

Analytical Standards

For Trace Elements

In Petroleum Products

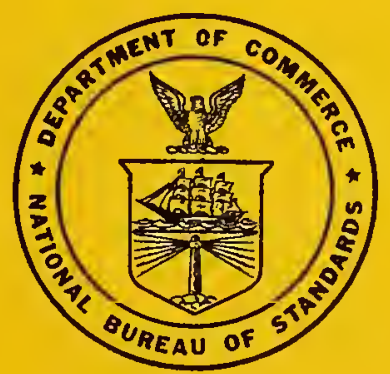

U.S. DEPARTMENT OF COMMERCE

NATIONAL BUREAU OF STANDARDS 


\section{THE NATIONAL BUREAU OF STANDARDS}

\section{Functions and Activities}

The functions of the National Bureau of Standards are set forth in the Act of Congress, March 3, 1901, as amended by Congress in Public Law 619, 1950. These include the development and maintenance of the national standards of measurement and the provision of means and methods for making measurements consistent with these standards; the determination of physical constants and properties of materials; the development of methods and instruments for testing materials, devices, and structures; advisory services to government agencies on scientific and technical problems; invention and development of devices to serve special needs of the Government; and the development of standard practices, codes, and specifications. The work includes basic and applied research, development, engineering, instrumentation, testing, evaluation, calibration services, and various consultation and information services. Research projects are also performed for other government agencies when the work relates to and supplements the basic program of the Bureau or when the Bureau's unique competence is required. The scope of activities is suggested by the listing of divisions and sections on the inside of the back cover.

\section{Publications}

The results of the Bureau's research are published either in the Bureau's own series of publications or in the journals of professional and scientific societies. The Bureau itself publishes three periodicals available from the Government Printing Office: The Journal of Research, published in four separate sections, presents complete scientific and technical papers; the Technical News Bulletin presents summary and preliminary reports on work in progress; and Basic Radio Propagation Predictions provides data for determining the best frequencies to use for radio communications throughout the world. There are also five series of nonperiodical publications: Monographs, Applied Mathematics Series, Handbooks, Miscellaneous Publications, and Technical Notes.

A complete listing of the Bureau's publications can be found in National Bureau of Standards Circular 460, Publications of the National Bureau of Standards, 1901 to June 1947 (\$1.25), and the Supplement to National Bureau of Standards Circular 460, July 1947 to June 1957 (\$1.50), and Miscellaneous Publication 240, July 1957 to June 1960 (Includes Titles of Papers Published in Outside Journals 1950 to 1959) (\$2.25); available from the Superintendent of Documents, Government Printing Office, Washington, D.C. 
UNITED STATES DEPARTMENT OF COMMERCE • Luther H. Hodges, Secretary NATIONAL BUREAU OF STANDARDS • A. V. Astin, Director

\section{Analytical Standards for Trace Elements in Petroleum Products}

H. S. Isbell, R. Stuart Tipson, J. L. Hague, B. F. Scribner,

W. Harold Smith, Clarence W. R. Wade, and Alex Cohen

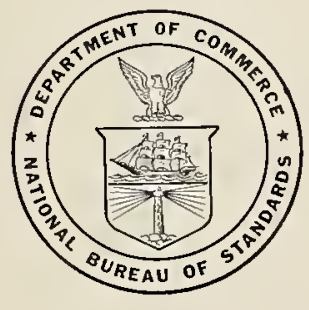

National Bureau of Standards Monograph 54

Issued October 1, 1962 



\section{Contents}

1.1. Origin and history of the project

1.2. Outline of the problem $\ldots \ldots$

1.3. Outline of the project._.

2. Discussion of the work done

2.1. Exploratory study of available compounds...........................

2.2. Compounds prepared and studied......

2.2.1. Metal salts of carboxylic acids and of dialkyldithiocarbamic acids._.....

2.2.2. Chelate compounds

a. Chelate compounds of azomethines (Schiff bases)

b. Chelate compounds of diketones and hydroxy ketones...

2.2.3. Miscellaneous compounds _._._._. 5

2.3. Evaluation of compounds__._. 5

2.3.1. Cooperative tests_._.

2.3.2. Spectrographic analysis _........ 5

2.3.3. Chemical analysis _._._._._. 6

2.3.4. Weight-stability of standard com-

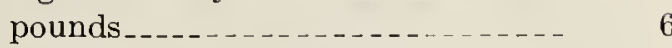

2.3.5. Dissolution in petroleum oils _____ 6

3. Experimental procedures

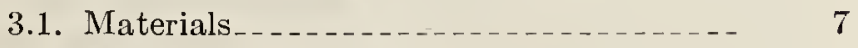

3.2. Drying of produets_._._. 7

3.3. Preparation of solubilizing agents_._._. 7

3.3.1. Bis(2-ethylhexyl)dith i o a r b a m i c acid.

7

3.3.2. 6-Methyl-2,4-heptanedione _...... 7

3.4. Preparation of compounds chosen as standards.
3. Experimental procedures-Continued

Page

3.4. Preparation of compounds, ete.-Con.

3.4.1. Cyclohexanebutyrates........... 8

a. Preparation_..... 8

b. Recovery of cyclohexanebutyric

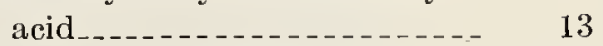

3.4.2. Miscellaneous compounds _........ 13

3.5. Other compounds investigated _...... 15

3.5.1. Erucates and 2-ethylhexanoates..... I5

3.5.2. Dialkyldithiocarbamates _._. _... 15

3.5.3. Azomethine chelates_............ 15

3.6. Spectrographic analysis_.......... 16

3.7. Chemical analysis____._. 16

3.7.1. Wet-ashing: ignition _........ 17

3.7.2. Wet-ashing__._._.

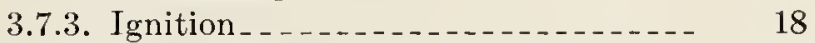

3.7.4. Other procedures___._.

3.8. Weight-stability of standards _____. 18

3.9. Dissolution in petroleum oils_____._. 19

3.9.1. Metal 2-ethylhexanoates _........ 20

3.9.2. Metal erucates_._._._._._._._. 20

3.9.3. Metal dialkyldithiocarbamates____. 20

3.9.4. Metal chelates of azomethines_._._- 21

3.9.5. Metal chelates of diketones and hydroxy ketones............ 21

3.9.6. Metal cyclohexanebutyrates_._._. 21

3.9.7. Miscellaneous compounds_........ 21

3.9.8. Preparation of an oil solution containing one element of interest, at the desired concentration

3.9.9. Preparation of an oil solution containing several elements of interest, at the desired concentration.

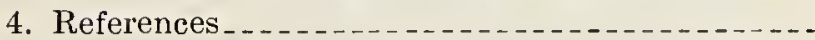

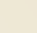

5

6

8

8

(8)

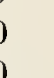

1





\title{
Analytical Standards for Trace Elements in Petroleum Products ${ }^{1}$
}

\author{
H. S. Isbell, R. Stuart Tipson, J. L. Hague, B. F. Scribner, W. Harold Smith, ${ }^{2}$ \\ Clarence W. R. Wade, and Alex Cohen
}

\begin{abstract}
A search has been conducted for stable, oil-soluble, organic compounds of metals (and other elements) for use in the spectrographic analysis of petroleum products. Compounds having suitable physical properties have been selected as standards in the determination of the following 24 elements: aluminum, barium, boron, cadmium, calcium, chromium, cobalt, copper, iron, lead, lithium, magnesium, manganese, mercury, nickel, phosphorus, potassium, silicon, silver, sodium, strontium, tin, vanadium, and zinc. The compounds have been purified and analyzed, and are available as certified standards. ${ }^{3}$

These stable, oil-soluble standards were selected from over 150 prospective compounds described in the Monograph. Methods are given for preparation of the compounds and for the spectrographic and chemical analysis of the chosen standards. Procedures are described for the preparation of stable solutions thereof in petroleum oils. Xylene, together with 2-ethylhexanoic acid, 6-methyl-2,4-heptanedione, and 2-ethylhexylamine (and specified mixtures thereof) are used as additives to render the various samples soluble. The resulting solutions are all compatible with each other, so that blends containing a known amount of each element of interest can be prepared as needed.
\end{abstract}

\section{Introduction}

\subsection{Origin and History of the Project}

Technological advances in the pctroleum industry during the past 15 years have occasioned a need for quantitative determination of metallic and other constituents present in petroleum and related products. For example, spectrographic determination of the content of certain elements in lubricating oils after use of the oils in engines provides a simple mcans for judging engine wear and serves as a guide in maintaining the equipment in a satisfactory operating condition. The research laboratories of petroleum companies have devoted much attention to developing spectrographic methods for determination of trace elements in petroleum products, but have been handicapped by a lack of suitable, pure, oil-soluble compounds (containing the elements of intcrest) that could be used as standards.

Recognizing the nced for standards for instrumental and chemical analysis for metals and other elements in petroleum products, the Committee on Analytical Research, Division of Refining, American Pctroleum Institute, proposed that the National Bureau of Standards develop and distribute a series of reproducible, stable, nonvolatilc, oil-soluble compounds (preferably solid) suitable for use as analytical, spectrographic standards.

1 This Monograph is based on work partly supported by the Committee on Analytical Research, Division of Refining, American Petroleum Institute. 2 Deceased, May 14, 1959.

3 These standard samples, prepared in solid form for easy weighing and handling, may be purchased for $\$ 10.00$ per $5 \mathrm{~g}$ of material. A certificate of analysis, plus directions for preparing a solution of the substance, is distributed with each samplc. Orders should be directed to the Standard Samples Clerk, National Bureau of Standards, Washington 25, D.C.
As the result of informal conferences and correspondence, the Committee on Analytical Research prepared an outline of the work desired and made a contract with the Chemistry Division of the National Bureau of Standards for the development of a series of 24 such analytical standards containing, respectively, aluminum, barium, boron, cadmium, calcium, chromium, cobalt, copper, iron, lead, lithium, magnesium, manganese, mercury, nickel, phosphorus, potassium, silicon, silver, sodium, strontium, tin, vanadium, and zinc. These standards were to be distributed undcr the NBS standard-materials program.

\subsection{Outline of the Problem}

Certain trace elements are present in petroleum products, as residues from crudes carried over in the refining process or as constituents of materials added to improve the lubricating properties or to lessen corrosive effects or oxidation. For many years, analytical chemists in the petroleum industry have had the problems of (a) determining minor elements, particularly metals, in petroleum and (b) establishing the accuracy and reliability of their methods. The analysis usually involves the addition of an accurately known amount of an oilsoluble compound of the clement in question to an oil which contains none of this element; the resulting standard solution is carried through all the steps of the method and the amount of the element added is determined. The same procedure is applied to the "unknown" oil, and its content of the elenient is determined by comparison. 
The problem of finding suitable metallo-organic compounds for use as standards has increased as more additives have been introduced and as a more exact knowledge of the trace constituents of petroleum and related products has been needed. However, the commercial metallo-organic compounds available were found to be not completely satisfactory as standards because (1) metallic and other contaminants are often present in these compounds in amounts greater than that of the trace element to be determined in the petroleum product; (2) some of the compounds are not sufficiently soluble in petroleum products; (3) some of the compounds are sufficiently volatile that considerable loss occurs during (or even before) the analysis; and (4) when combinations of the elements (as their respective compounds) were dissolved in a single oil, the compounds often gave incompatible mixtures.

In 1955, the Committee on Analytical Research, Division of Refining, American Petroleum Institute realized that the devclopment of suitable standards for chemical analysis and for analysis by emission spectrography, X-lay fluorescence, flame photometry, or colorimetry was a pressing need. A survey revealed that 24 elements, mainly metals, were of particular interest in the analysis of crudes, charge stocks, and finished petroleum products.

\subsection{Outline of the Project}

When this project was started, oil-soluble naphthenates, sulfonates, or hexanoatcs of most of the metals of interest wcre available, as were compounds of boron, phosphorus, and silicon. However, few of these were spectroscopically pure, many were unstable under conditions of use, and most of them were unsuitable as standards for analytical determinations. Moreover, methods for the preparation of the pure compounds were unavailable.

Although certain naphthcnates and petroleum sulfonates had been used as standards, naphthenic acids and petroleum sulfonic acids are mixtures having a composition which may differ from batch to batch, and commercial products now available might well differ from materials available in the future. To secure standards that would not differ according to the source, it was decided to prepare a series of more-readily duplicated standards. Consequently, attention was directed to the preparation of definite, reproducible, oil-soluble compounds (prefcrably solid) of the 24 elements selected by the Committee.

Another object of the project was to develop methods for preparing suitablc blcnds of the standards in an appropriate base oil, so that possession of an adequate collcction of oil-soluble compounds would permit preparation of any desired blend (of known concentrations) at any time and make it unnecessary to maintain a variety of standardized blends.

After consultation with the Advisory Committee, the following program was developed.

(1) Tentative sclection of general classes of compounds having the desired properties, from indications obtaincd by a search of the literature and by correspondence with industry.

(2) Qualitative examination of available matcrials to ascertain thcir suitability for use as standards.

(3) Preparation and purification of potentially useful compounds.

(4) Determination of pertinent properties of potcntially useful compounds.

(5) Selection of specific compounds for use as standards.

(6) Development of methods for preparing oil solutions of the standard compounds.

(7) Preparation of large batches of the standard compounds.

(8) Spectroscopic and chemical analysis of the standard compounds.

(9) Sale and distribution, through the NBS standard-materials program, of the sclected compounds as certified standards for analytical use.

\section{Discussion of the Work Done}

\subsection{Exploratory Study of Available Compounds}

The literature submitted to us by the Project Study Group of the Committce was reviewed, and requests were made to all prospective suppliers of oil-soluble, metallo-organic compounds for information concerning potentially useful compounds that they might be able to supply. About 40 samples of commercial compounds were obtained and preliminary tests were made in order to ascertain whether these might prove suitable for use as standards.

\subsection{Compounds Prepared and Studied}

In order to form an opinion as to the kinds of compounds most likely to be suitable for use as standards, the chemical litcrature was studied, a large number of potentially useful compounds were prepared, and qualitative tests of their solubility and stability were made. From the results of these studies, the compounds that seemed most suitable were then selected for further study; these are briefly discussed in the next three sections.

Table 1 lists the salts prepared and examined. Those italicized werc distributed to cooperators in the petroleum industry, for qualitative evaluation. From the results of these and other tests, the compounds listed in table 2 were selected as the most promising; those italicized were prepared and distributed in 1958 to workers wishing to examine thcm for possible use as standards. 
TABLE 1. Exploratory study of salts of metals a

\begin{tabular}{|c|c|c|c|c|c|c|c|c|c|c|c|c|c|c|c|c|c|c|c|c|}
\hline Salt of & $\mathrm{Al}$ & $\mathrm{Ba}$ & $\mathrm{Cd}$ & $\mathrm{Ca}$ & $\mathrm{Cr}$ & Co & $\mathrm{Cu}$ & $\mathrm{Fe}$ & $\mathrm{Pb}$ & $\mathrm{Li}$ & $\mathrm{Mg}$ & Mn & $\mathrm{Hg}$ & $\mathrm{Ni}$ & $\mathrm{K}$ & $\mathrm{Na}$ & $\mathrm{Sr}$ & Sn & $\mathrm{V}$ & $\mathrm{Zn}$ \\
\hline $\begin{array}{l}\text { A. Carboxylic Acids } \\
\text { 1. Naphthenic acids } \\
\text { 2. Cyclobexanebutyric acid } \\
\text { 3. 2-Etbylbexanoic aeid } \\
\text { 4. Palmitie acid } \\
\text { 5. Oleic acid } \\
\text { 6. Erucic acid }\end{array}$ & $\begin{array}{l}\mathrm{Xb} \\
\mathrm{X} \\
\mathrm{X} \\
\mathrm{X} \\
\mathrm{X} \\
\mathrm{X}\end{array}$ & $\begin{array}{l}\mathrm{X} \\
\mathrm{x} \\
\mathrm{x} \\
\mathrm{x}\end{array}$ & $\begin{array}{l}\mathrm{x} \\
\mathrm{x}\end{array}$ & $\begin{array}{l}\mathrm{X} \\
\mathrm{x} \\
\mathrm{x} \\
\mathrm{X}\end{array}$ & $\begin{array}{l}\mathrm{x} \\
\mathrm{x} \\
\mathrm{x} \\
\mathrm{x}\end{array}$ & $\frac{\mathrm{x}}{\mathrm{X}}$ & $\begin{array}{l}\mathrm{x} \\
\mathrm{x} \\
\mathrm{x} \\
\mathrm{x}\end{array}$ & $\begin{array}{l}\mathrm{x} \\
\mathrm{X} \\
\mathrm{X} \\
\mathrm{x}\end{array}$ & $\frac{\mathrm{X}}{\mathrm{X}}$ & $\frac{\mathrm{x}}{\mathrm{x}}$ & $\begin{array}{l}\mathrm{Xb} \\
\mathrm{X} \\
\mathrm{X} \\
\mathrm{X} \\
X\end{array}$ & $\begin{array}{l}\mathrm{X} \\
\mathrm{X} \\
\mathrm{X} \\
\mathrm{X}\end{array}$ & $\frac{\mathrm{x}}{\mathrm{x}}$ & $\begin{array}{l}\mathrm{X} \\
\mathrm{X} \\
\mathrm{X} \\
\mathrm{X}\end{array}$ & $X$ & $\begin{array}{l}\mathrm{X} \\
\mathrm{X} \\
\mathrm{X} \\
\mathrm{X}\end{array}$ & $\frac{\mathrm{x}}{\mathrm{x}}$ & & $\mathrm{X}$ & $\begin{array}{l}\mathrm{X} \\
\mathrm{X}\end{array}$ \\
\hline $\begin{array}{l}\text { B. Dithioearbamic Acids } \\
\text { 1. Dietbyl- } \\
\text { 2. Diisopropyl- } \\
\text { 3. Dibutyl- } \\
\text { 4. Disopentyl- } \\
\text { 5. Bis(1,3-dimethylbuty } 1 \text { - }\end{array}$ & $\underset{\mathrm{X}}{\mathrm{X}}$ & $\mathrm{X}$ & $X$ & $\begin{array}{l}\mathrm{X} \\
\mathrm{X}\end{array}$ & $\begin{array}{l}\mathrm{X} \\
\mathrm{X}^{\mathrm{b}}\end{array}$ & $\begin{array}{l}\mathrm{X} \\
\mathrm{X} \\
\mathrm{X} \\
\mathrm{X} \\
\mathrm{X}\end{array}$ & $\begin{array}{l}\mathrm{x} \\
\mathrm{x} \\
\mathrm{X}\end{array}$ & $\begin{array}{l}x \\
x \\
x \\
x \\
x\end{array}$ & $\begin{array}{l}\mathrm{X} \\
\mathrm{X}\end{array}$ & $\mathrm{X}$ & $\begin{array}{l}\mathrm{X} \\
\mathrm{X}\end{array}$ & $\begin{array}{l}\mathrm{X} \\
\mathrm{X} \\
\mathrm{X} \\
\mathrm{X}\end{array}$ & $x$ & $\underset{\mathrm{X}}{\mathrm{X}}$ & $\mathrm{x}$ & $\begin{array}{l}\mathrm{x} \\
\mathrm{X} \\
\mathrm{X} \\
\mathrm{X} \\
\mathrm{X}\end{array}$ & & $X$ & $\underset{X}{X}$ & $\begin{array}{l}X \\
X\end{array}$ \\
\hline $\begin{array}{l}\text { 6. Dibeptyl- } \\
\text { 7. Dicyclobexyl- } \\
\text { 8. Bis(2-tbylhexyl)- } \\
\text { 9. 2-Ethylbexyl- } \\
\text { 10. Hexadecyl- } \\
\text { 11. Cyclobexyl- }\end{array}$ & $\begin{array}{l}\mathrm{X} \\
\mathrm{X} \\
\mathrm{X} \\
\mathrm{X}\end{array}$ & $\begin{array}{l}\mathrm{X} \\
\mathrm{X}\end{array}$ & & $\underset{\mathrm{X}}{\mathrm{X}}$ & $\begin{array}{l}\mathrm{X} \\
\mathrm{X} \\
\mathrm{X} \\
\mathrm{X} \\
\mathrm{X}\end{array}$ & $\begin{array}{l}\mathrm{X} \\
\mathrm{X} \\
\mathrm{X}^{r} \\
\mathrm{X} \\
\mathrm{X}\end{array}$ & $\begin{array}{l}\mathrm{X} \\
\mathrm{X} \\
\mathrm{X}\end{array}$ & $\begin{array}{l}\mathrm{X} \\
\mathrm{X} \\
\mathrm{X} \\
\mathrm{X}\end{array}$ & $\mathrm{x}$ & $\begin{array}{l}\mathrm{X} \\
\mathrm{X}\end{array}$ & $\begin{array}{l}\mathrm{X} \\
\mathrm{X} \\
\mathrm{X}\end{array}$ & $\begin{array}{l}\underset{\mathrm{X}}{\mathrm{X}} \\
\mathrm{X}\end{array}$ & & $\underset{X}{\mathrm{X}}$ & $\begin{array}{l}\mathrm{X} \\
\mathrm{X} \\
\mathrm{X}\end{array}$ & $\begin{array}{l}\mathrm{X} \\
\mathrm{X} \\
\mathrm{X} \\
\mathrm{X} \\
\mathrm{X} \\
\mathrm{X}\end{array}$ & & & $\begin{array}{l}\frac{\mathrm{X}}{\mathrm{X}} \\
\mathrm{X} \\
\mathrm{X}\end{array}$ & $\begin{array}{l}\mathrm{X} \\
\mathrm{X}\end{array}$ \\
\hline
\end{tabular}

- The symbol X indicates that tbis salt was prepared; an italic $X$ indieates tbat a sample of this salt was cvaluated by eooperators in the petroleum industries. b Oily product which did not erystallize.

TABIE 2. First set of compounds selected as possible standards a

(April 11, 1958)

\begin{tabular}{|c|c|}
\hline Element & Compound \\
\hline $\begin{array}{l}\text { 1. Aluminum } \\
\text { 2. Barium } \\
\text { 3. Boron } \\
\text { 4. Cadmium } \\
\text { 5. Calcium }\end{array}$ & $\begin{array}{l}\text { 2-ethylhexanoate } \\
\text { (a) erucate; (b) bis(2-ethylhexyl)dithioearbamate } \\
\text { (a) tris (2-cyclohexylcyclohexyl) borate; (b) tris(diso- } \\
\text { butylcarbinyl) borate } \\
\text { dibutyldithiocarbamate } \\
\text { (a) erucate; (b) 2-ethylhexanoate }\end{array}$ \\
\hline $\begin{array}{l}\text { 6. Chromium } \\
\text { 7. Cobalt } \\
\text { 8. Copper } \\
\text { 9. Iron } \\
\text { 10. Lead }\end{array}$ & $\begin{array}{l}\text { (a) oleate; (b) erucate } \\
\text { (a) dibutyldithiocarbamate; (b) bis(2-etbylhexyl)dithio- } \\
\text { carbamate } \\
\text { (a) dibutylditbiocarbamate; (b) bis (N-salicylidene-2- } \\
\text { ethylhexylamine) chelate } \\
\text { (a) dibutyldithiocarbamate; (b) diisopropylditbiocarba- } \\
\text { mate } \\
\text { dibutyldithiocarbamate }\end{array}$ \\
\hline $\begin{array}{l}\text { 11. Lithium } \\
\text { 12. Magnesium } \\
\text { 13. Manganese } \\
\text { 14. Mercury } \\
\text { 15. Nickel }\end{array}$ & $\begin{array}{l}\text { (a) erucate; (b) dieyclobexylditbiocar bamate } \\
\text { erucate } \\
\text { (a) cyclohexanebutyrate; (b) oleate } \\
\text { dibutyldithiocarbamate } \\
\text { (a) dibutyldithiocarbamate; (b) bis (2-ethylhexyl)dithio- } \\
\text { carbamate: (c) bis(N-salicylidene-2-ctbylbexyla- } \\
\text { mine) cbelate }\end{array}$ \\
\hline $\begin{array}{l}\text { 16. Pbospborus } \\
\text { 17. Potassium } \\
\text { 18. Silicon }\end{array}$ & $\begin{array}{l}\text { triphenyl phosphate } \\
\text { (a) erucate: (b) bis(2-etbylbexyl)dithioearbamate; } \\
\text { (c) dieyelohexylditbiocarbamate } \\
\text { octaphenylcyclotetrasiloxane }\end{array}$ \\
\hline 20. Sodium & (a) erucate; (b) dicyclohexyldithiocarbamate \\
\hline $\begin{array}{l}\text { 21. Strontium } \\
\text { 22. Tin } \\
\text { 23. Vanadium } \\
\text { 24. Zine }\end{array}$ & $\begin{array}{l}\text { erucate } \\
\text { dibutyldithiocarbamate } \\
\text { bis(salicylaldehyde oxime) cbelate } \\
\text { dibutyldithiocatbamate }\end{array}$ \\
\hline
\end{tabular}

* The eompounds italieized were eralunted by eooperators in the petroleum industries.

As a result of these tests, the compounds listed in table 3 were selected for further study. (UJtimately, the compounds listed in table 6 were chosen as standards.)

\subsubsection{Metal Salts of Carboxylic Acids and Dialkyldi-} thiocarbamic Acids

Salts of carboxylic acids (see table 1) were prepared by one or other of the following methods.
TABLE 3. Second set of compounds selected for consideration as standards

(Sept. 30, 1958)

\begin{tabular}{|c|c|}
\hline Element & Compound \\
\hline $\begin{array}{l}\text { 1. Aluminum } \\
\text { 2. Barium } \\
\text { 3. Boron } \\
\text { 4. Cadmium } \\
\text { 5. Calcium }\end{array}$ & $\begin{array}{l}\text { (a) 2-ethylbexanoate; (b) cyclohexanebutyrate } \\
\text { (a) erucate; (b) 2-etbylhexanoate } \\
\text { menthyl borate } \\
\text { (a) dibutyldithiocarbamate; (b) cyclohexanebuty- } \\
\text { rate } \\
\text { 2-etbylhexanoate }\end{array}$ \\
\hline $\begin{array}{l}\text { 6. Cbromium (III) } \\
\text { 7. Cobalt (II) } \\
\text { 8. Copper } \\
\text { 9. Iron (III) } \\
\text { 10. Lead }\end{array}$ & 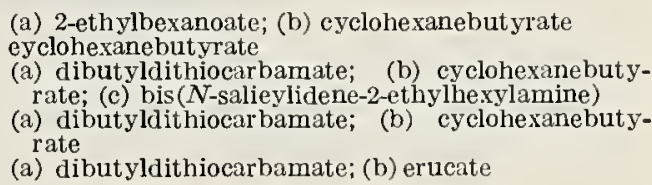 \\
\hline $\begin{array}{l}\text { 11. Litbium } \\
\text { 12. Magnesium } \\
\text { 13. Manganese } \\
\text { 14. Mercury } \\
\text { 15. Niekel }\end{array}$ & 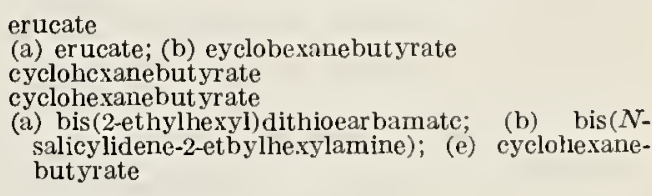 \\
\hline $\begin{array}{l}\text { 16. Pbosphorus } \\
\text { 17. Potassium } \\
\text { 18. Silicon } \\
\text { 19. Silver } \\
\text { 20. Sodium }\end{array}$ & $\begin{array}{l}\text { tripbenyl pbosphate } \\
\text { erucate } \\
\text { octapbenyleyclotetrasiloxane } \\
\text { cyclohexanebutyrate } \\
\text { (a) erucate; (b) cyelohexanebutyrate }\end{array}$ \\
\hline $\begin{array}{l}\text { 21. Strontium } \\
\text { 22. Tin (IV) } \\
\text { 23. Vanadium } \\
\text { 24. Zinc }\end{array}$ & 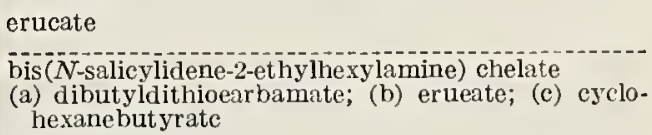 \\
\hline
\end{tabular}

(a) Sodium salt of the acid plus a salt of the metal

$$
n \mathrm{RCOONa}+\mathrm{M}^{n+} \rightarrow(\mathrm{RCOO})_{n} \mathrm{M}+n \mathrm{Na}^{+} .
$$

(b) 'The acid plus the metal hydroxide

$$
n \mathrm{RCOOH}+\mathrm{M}(\mathrm{OH})_{n} \rightarrow(\mathrm{RCOO})_{n} \mathrm{M}+n \mathrm{H}_{2} \mathrm{O} \text {. }
$$

(c) The acid plus the metal oxide

$$
2 n \mathrm{RCOOH}+\mathrm{M}_{2} \mathrm{O}_{n} \rightarrow 2(\mathrm{RCOO})_{n} \mathrm{M}+\mathrm{H}_{2} \mathrm{O} .
$$


(d) (For aluminum) The acid plus aluminum isopropoxide

$3 \mathrm{RCO}_{2} \mathrm{H}+\mathrm{Al}\left(\mathrm{OC}_{3} \mathrm{H}_{7}\right)_{3} \rightarrow\left(\mathrm{RCO}_{2}\right)_{3} \mathrm{Al}+3 \mathrm{C}_{3} \mathrm{H}_{7} \mathrm{OH}$.

(e) The acid plus the metal acetate

$$
n \mathrm{RCOOH}+\mathrm{M}(\mathrm{OAc})_{n} \rightarrow(\mathrm{RCOO})_{n} \mathrm{M}+n \mathrm{HOAc} .
$$

Although the naphthenates were found to have suitable oil-solubilities, they were not chosen as standards because of lack of uniformity of naphthenic acid. In addition to the salts listed in table 1, silver erucate, dibutyltin 2-ethylhexanoate, and silver cyclohexanebutyrate were prepared. The salts of 2-ethylhexanoic acid and cyclohexanebutyric acid were found to be much less soluble than the salts of naphthenic acid, but most of them had the advantage of being definite, reproducible compounds.

Most of the compounds listed in table 1 were obtained as solids, many of them crystalline. Before and after purification, the approximate solubility in such common organic solvents as benzene, xylene, chloroform, alcohol, and ether was ascertained. (This information also served as a guide to the probable degree of solubility in petroleum oils.) For purification of carboxylic acid salts, butyl acetate was found to be a general solvent, but chloroform, ethanol, aqueous acetone, and water were preferable in some instances. Acetone was used as a general precipitant for all of the cyclohexanebutyrates.

Many salts of the dialkyldithiocarbamic acids were prepared according to the following equations.

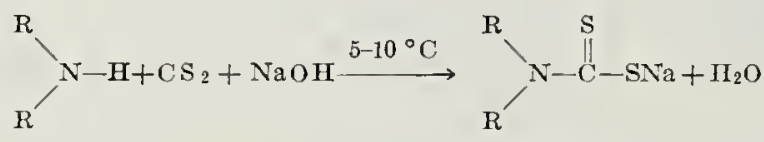

$$
n \mathrm{R}_{2} \mathrm{~N}-\stackrel{\mathrm{C}}{\|} \mathrm{SNa}+\mathrm{M}^{n+} \rightarrow\left(\mathrm{R}_{2} \mathrm{NC}_{\mathrm{C}}-\mathrm{S}\right)_{n} \mathrm{M}+n \mathrm{Na}^{+}
$$

where $\mathrm{M}=\mathrm{Cu}^{++}, \mathrm{Al}^{+++}$, etc.

Because of their ease of preparation, low solubility in water, and characteristic colors, these salts have been extensively used as organic reagents for the detection and quantitative estimation of many metals. Their solubilities in paraffin or lubricating oils have not, however, been recorded in the literature.

Some of these salts lack stability, but others seemed promising. In general, the heavy-metal salts are insoluble in water but soluble in such low-polarity solvents as benzene, chloroform, carbon tetrachloride, and carbon disulfide. Benzene, chloroform, and ethanol were satisfactory solvents for recrystallization.

The salts of diethyldithiocarbamic acid crystallize readily, but are only slightly soluble in hot paraffin oil. The salts of dicyclohexyldithio- carbamic acid also have low solubility in paraffin oil. The salts of dibutyldithiocarbamic acid are more soluble; crystalline dibutyldithiocarbamates of cadmium, cobalt, copper, iron, lead, mercury, nickel, and zinc were prepared and found to have many desirable properties, but salts of the other metals were less satisfactory. Salts of bis(2ethylhexyl)dithiocarbamic acid have excellent solubility, but are much more difficult to isolate and purify than the salts of the other carbamic acids mentioned; only the nickel salt was satisfactory. In addition to the salts listed in tables 1,2 , and 3 , some salts of 1,1,3,3-tetramethylbutyldithiocarbamic acid were prepared, but their properties were unsuitable.

The solubility of dialkyldithiocarbamates in lubricating oils is increased by the addition of bis(2-ethylhexyl) dithiocarbamic acid.

\subsubsection{Chelate Compounds}

For a given metal, a variety of metallo-organic complexes were prepared and studied, in order to evaluate (1) the methods of preparation; (2) the increase or decrease in solubility caused, in a given class of chelates, by change of the bonding groups and by branching or lengthening of the alkyl side-chain; and (3) the relative stability of various chelates.

Compounds examined in a cursory fashion included metal derivatives of cupferron, dimethylglyoxime, $\alpha, \alpha$-(ethylenedinitrilo) di-o-cresol, 1-nitroso-2-naphthol, 8-quinolinol, picolinic acid, rhodanilic acid, and the oximes of salicylaldehyde, $1^{\prime}$-liydroxy-2'-acetonaphthone, and 2'-hydroxyacetophenone.

Compounds prepared and examined in more detail were various metal derivatives of (a) $N$ salicylidenebutylamine and $N$-salicylidene-2-ethylhexylamine, and (b) 1,3-diphenyl-1,3-propanedione, 2,4-hexanedione, 1'-hydroxy-2'-acetonaphthone, $\quad 2$-hydroxyacetophenone, 6-methyl-2,4heptanedione, 2,4-pentanedione, and 1-phenyl-1,3butanedione.

\section{a. Chelate Compound, of Azomethines (Schif Bases)}

The azomethines and their metal complexes were prepared by the following reactions:

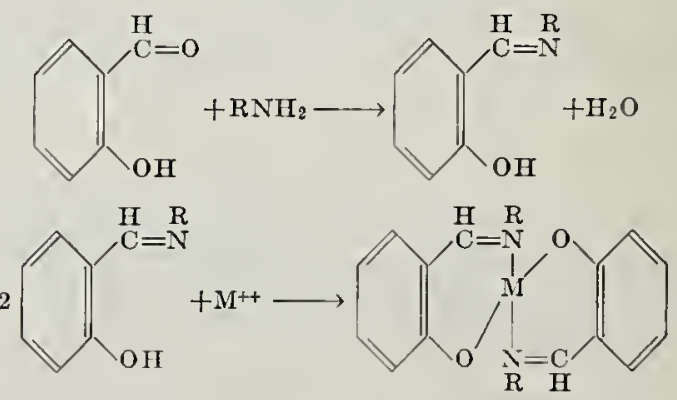

where $\mathrm{R}=$ alkyl, and $\mathrm{M}^{++}=$a metal ion.

Work was conducted on these chelates of cadmium, cobalt, copper, iron, nickel, vanadium, and zinc. Of these, the crystalline complexes of cop- 
per, nickel, and vanadium seemed the most promising. However, the vanadium compounds are not sufficiently stable for use as standards.

\section{b. Chelate Compounds of Diketones and Hydroxy Ketones}

In general, chelates of the ketones were prepared according to one of the following equations:
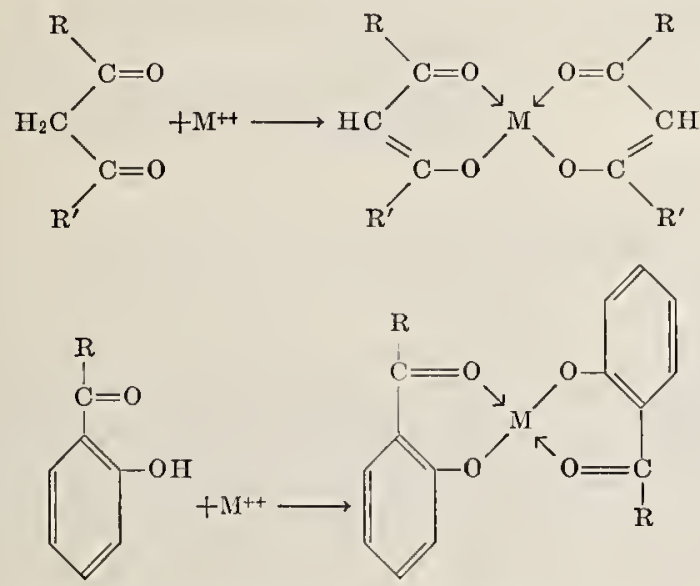

where $\mathrm{R}=\mathrm{H}$ or $\mathrm{CH}_{3}$, and $\mathrm{R}^{\prime}=$ alkyl or phenyl.

For aluminum and chromium, liquid chelates of 6-methyl-2,4-heptanedione were prepared [1] efforts to crystallize these compounds were unsuccessful.

The 2,4-pentanedione chelates of aluminum, cadmium, chromium, cobalt, copper, iron, nickel, and vanadium were prepared; the solubilities of these compounds in lubricating oils were found to be unsatisfactory.

Finally, the 1-phenyl-1,3-butanedione chelates of chromium, cobalt, iron, lead, and vanadium were prepared. Of these compounds, the chelates of cobalt, lead, and vanadium seemed the most promising. Only the vanadium compound was then studicd in detail because (a) a suitable vanadium compound had high priority and (b) this diketone is too expensive for consideration unless no other suitable derivative could be found.

\subsubsection{Miscellaneous Compounds}

A number of miscellaneous compounds were studied.

(a) Triphenyl phosphate. A supply of triphenyl phosphate was purchased. 'The ester was purified by recrystallization from ethanol and from aqueous ethanol, and its solubilities were studied. A spectrographic analysis of the material indicated that it would make a satisfactory standard.

(b) Borates. 2-Cyclohexylcyclohexyl borate was prepared. It was found to contain impurities that separated from solutions of the material in oil. Since the impurities were not readily removed, other borates were examined. Menthyl borate was prepared, and it was found to have satisfactory solubility in lubricating oils.

(c) Octaphenylcyclotetrasiloxane. Use of this compound as a standard for silicon was suggested

4 Figures in braekets indicate the literature referenees at the end of this Monograph. by E. G. Tajkowski of the Silicone Products Department, General Electric Company, Waterford, N.Y., and he kindly supplied the material tested. 'The sample was found to be exceptionally pure and to be suitable for use without further treatment. It had certain desirable properties, but low solubility in lubricating oils.

(d) Other compounds studied included ferric 2methylpentanoate, mercuric 2-methylpentanoate, aluminum 2-ethylhexanoate, calcium 2-ethylhexanoate, iron 2-ethylhexanoate, silver 2-ethylhexanoate, and potassium erucate.

\subsection{Evaluation of Compounds}

\subsubsection{Cooperative Tests}

In the evaluation of samples of our compounds in laboratories of the petroleum industries, the following were the cooperative tests made and the cooperators.

Solubility, stability, and compatibility. California Research (R. L. Le'Tourneau), Esso Research and Engineering (H. L. Leland), Gulf Research (R. O. Clark), Phillips Petroleum (B. J. Heinrich), Shell Development (E. D. Peters), Standard Oil of Indiana (E. B. Tucker), Texaco Research (F. M. Roberts), Union Oil (G. R. Lake).

Volatility. E. I. du Pont de Nemours (G. H. Patterson), Ethyl Research (C. M. Gambrill).

At the meeting of our group with the Advisory Committee on January 16, 1959, the following decisions were then reached:

(1) To discontinue study of salts of naphthenic acid, because the acid is a variable mixture of acids that may differ from batch to batch.

(2) To avoid use of dithiocarbamates, because, in some projected uses of the standards, introduction of sulfur would be undesirable, particularly in X-ray fluorescence studies.

(3) To continue study of salts of cyclohexanebutyric acid (in preference to salts of erucic acid and 2-ethylhexanoic acid), because they are more readily isolated as solid matcrials.

(4) To continue search for a suitable compound of vanadium.

(5) To proceed with preparation of large batches of compounds selected as standards, and to purify, analyze, and issue them as provisional standards.

These decisions were then acted on. In connection with item 4, bis(1-phenyl-1,3-butanediono)oxovanadium (IV) was prepared, tested, and selected as the vanadium standard.

\subsubsection{Spectrographic Analysis}

Qualitative tests on the compounds prepared during the exploratory part of the project indicated that there would be no particular difficulty in obtaining reasonably pure materials for use as standards. After the program had become restricted to products to be used as standards, semiquantitative spectrographic measurements 
(and chemical analyses) were made on a sample taken from the final, highly purified batch of each standard compound. The procedure for, and results of, spectrographic analysis of the standard compounds are given in section 3.6.

\subsubsection{Chemical Analysis}

Each standard sample was analyzed by appropriate methods, the details of which are given in section 3.7. Table 4 lists the various methods employed for decomposing the standard samples, prior to analysis. The analytical results are given in table 6 .

TABLE 4. Methods used for decomposition of standard. samples

\begin{tabular}{|c|c|}
\hline Method & Standard Sample No. ${ }^{\mathrm{a}}$ \\
\hline Sulfuric-nitric acids & $\begin{array}{l}1050,1051,1052,1052 \mathrm{a}, 1053,1054,1056, \\
\quad 1056 \mathrm{a}, 1057,1057 \mathrm{a}, 1058,1059,1060,1061, \\
1061 \mathrm{a}, 1062,1062 \mathrm{a}, 1065,1065 \mathrm{a}, 1066,1067, \\
1070,1071,1072,1073,1075 .\end{array}$ \\
\hline Ignition & $\begin{array}{l}1050,1051,1051 \mathrm{a}, 1052,1052 \mathrm{a}, 1054,1055, \\
1055 \mathrm{a}, 1056,1058,1059,1059 \mathrm{a}, 1060 \mathrm{a}, 1061 \\
1062,1065,1067,1068,1069,1069 \mathrm{a}, 1070, \\
1070 \mathrm{a}, 1073,1073 \mathrm{a}, 1074,1075,1076,1077\end{array}$ \\
\hline Peroxide fusion & $1063,1063 a$ \\
\hline Extraction with chloroform & 1064 \\
\hline Perchloric-nitric acids $\ldots . . . . .$. & $1071 \mathrm{a}$ \\
\hline
\end{tabular}

a The name of each standard sample is given in tablc 6 . The letter a after the number of a standard sample indicates material obtained in a sccond, large-scale preparation.

\subsubsection{Weight-stability of Standard Compounds}

The weight-stability of each standard sample was determined by (a) exposing the sample to an atmosphere of 75 percent humidity for various periods of time, and then, after equilibrium had been reached, (b) drying the same sample over phosphorus pentaoxide. From the results, the drying times recommended in table 5 were obtained.

For those compounds which require only a 2-hr drying time, the maximum gain in weight on exposure to 75 percent humidity was 0.08 percent. The maximum loss in weight when these compounds were then dried over phosphorus pentaoxide was 0.05 percent.

From the results of this work, it is recommended that all specimens of the standard samples should be stored in closed containers in desiccators containing phosphorus pentaoxide.

\subsubsection{Dissolution in Petroleum Oils}

Since most of the solid, metallo-organic compounds that are stable in humid air are, for the intended use, too insoluble in lubricating oil, and since simple methods of dissolving these substances to give stable solutions had not been discovered, it had (before this project was undertaken) been customary to prepare oil solutions of the various compounds without isolating the solids.
TABLE 5. Time recommended for drying over phosphorus pentaoxide at room temperature

\begin{tabular}{|c|c|}
\hline Time & Standard Sample No.a \\
\hline$\quad h r$ & 1066 \\
\hline $2-\ldots-n$ & $\begin{array}{c}1050,1052 \mathrm{a}, 1056,1056 \mathrm{a}, 1057,1057 \mathrm{a}, 1059 \mathrm{a}, \\
1063,1063 \mathrm{a}, 1064,1071,1071 \mathrm{a}, 1076,1077\end{array}$ \\
\hline $24 \ldots$ & $\begin{array}{l}1051,1051 \mathrm{a}, 1055,1058,1060,1060 \mathrm{a}, 1068,1070 \\
\quad 1070 \mathrm{a}, 107 \mathrm{x}\end{array}$ \\
\hline 48 & $\begin{array}{c}1053,1054,1055 a, 1059,1061,1061 a, 1062,1065 \\
1065 a, 1069,1069 a, 1072,1073 a, 1074,1075\end{array}$ \\
\hline $72 \ldots$ & $1062 \mathrm{a}$ \\
\hline
\end{tabular}

a see footnote a to table 4 .

However, use of solid materials, which may be conveniently dried handled, and weighed, is advantageous. Nevertheless, successful application of the set of solid compounds we have developed is contingent on a simple reproducible method of preparing stable solutions of them in petroleum oils.

In many instances, application of heat causes the compound to dissolve in oil, but, on cooling to room temperature and standing for several days, gellation or precipitation often occurs in the solution.

For preparing stable oil-solutions containing the desired concentration of the respective element, several organic solubilizing agents were developed. These could be used in small proportions, and proved satisfactory for preparing single solutions or blends of the 24 metallo-organic standards. These agents may be loosely classified on the basis of their chemical properties and according to the types of compound they solubilize.

Xylene, which has a rather low volatility (high boiling point) was found to be satisfactory for predissolving the selected compounds of boron, phosphorus, silicon, and tin, and it was used, in combination with the other solubilizing agents found necessary, for predissolving all of the standard compounds.

Oil-soluble organic acids, especially naphthenic acid and 2-ethylhexanoic acid, were found to be excellent agents for dissolving the salts (soaps) of lead, manganese, mercury, nickel, zinc, and the alkali and alkaline-earth metals. To maintain compatibility of blends, it was found advisable to employ 2-ethylhexanoic acid with many of the non-soaps. Use of naphthenic acid was discontinued because of variability of the material.

2-Ethylhexylamine was found to solubilize salts of metals that form complexes with ammonia, for example, the salts of cadmium, cobalt, copper, nickel, and silver. Even in daylight, the oil solutions of silver formed in this way are stable for months. In order to stabilize solutions of vanadium for long periods of time, addition of 2,2'-diethyldihexylamine proved satisfactory. 
6-Methyl-2,4-heptanedione gives metal derivatives that are difficult to crystallize, and it was found excellent for predissolving the compounds of iron and chromium and for preventing formation of, or dissolving, gels of aluminum salts.
After a compound had been dissolved by use of one or more solubilizers, the solution could be diluted to the desired concentration with lubricating oil or with such hydrocarbons as mineral spirits, paraffin oil, gasoline, or heptane.

\section{Experimental Procedures}

\subsection{Materials}

The inorganic salts were reagent or analytical grade. The acetone, chloroform, absolute ethanol, and absolute methanol were reagent grade, and the butyl acetate was commercial material of 90- to 92-percent purity; all organic solvents were used without further purification. Cyclohexanebutyric acid (obtained from Distillation Products Industries, Eastman Organic Chemicals Department, Rochester 3, New York) was redistilled, and the fraction boiling at $134{ }^{\circ} \mathrm{C}(3 \mathrm{~mm})$ was collected and used for the preparation of its salts. Scrupulous precautions were taken to avoid contamination of all materials; apparatus was thoroughly cleaned, and dust was removed and excluded.

\subsection{Drying of Products}

After recrystallization or reprecipitation from an appropriate solvent, each purified product was air-dried overnight (with exclusion of dust), dried in a vacuum desiccator (enclosed in a Desiguard) over phosphorus pentaoxide at $0.5 \mathrm{~mm}$, ground with an agate mortar and pestle, and sieved to pass a 40-mesh screen. (For certain hard, noncrystalline, or slightly sticky products, it was necessary first to grind to pass a 20 -mesh sieve, redry, and then grind to pass a 40 -mesh sieve.) The compound was redried in a vacuum desiccator over phosphorus pentaoxide at $0.5 \mathrm{~mm}$, and, if necessary, large quantities were then placed in a rotary cylinder and dried at room temperature at $0.5 \mathrm{~mm}$, under continuous rotation, for at least $48 \mathrm{hr}$ (or until condensate was no longer formed in a dry-ice trap included in the system). Immediately preceding analysis (see sections 3.6 and 3.7), each sample was further dried, as described in section 3.8 .

\subsection{Preparation of Solubilizing Agents}

\subsubsection{Bis(2-ethylhexyl)dithiocarbamic Acid}

Cold carbon disulfide (7.6 g, 0.1 mole) was added dropwise, with stirring, to $44.3 \mathrm{~g}$ (0.2 mole) of cold bis(2-ethylhexyl)amine in an ice bath, at such a rate tbat the temperature of the mixture did not exceed $10^{\circ} \mathrm{C}$. Stirring was continued for an additional $10 \mathrm{~min}$, after which the reagent was poured into a bottle which was then stoppered. For many of the metallo-organic compounds, dissolution was facilitated by diluting the reagent with an equal volume of xylene.

\subsubsection{6-Methyl-2,4-heptanedione $[2]^{5}$}

Anhydrous, ethanol-free sodium ethoxide (2 moles, prepared from $46 \mathrm{~g}$ of granular sodium), anhydrous ethyl acetate (352.4 g, 4 moles), and 1 liter of sodium-dried toluene were placed in a 5-liter, 3-necked, round-bottomed flask equipped with a drying tube, a powerful melcury-sealed stirrer, and a 300-ml dropping funnel equipped with a drying tube. The mixture was stirred for 30 min at room temperature, cooled in an ice bath, and vigorously stirred while 4-methyl-2pentanone (200.3 g, 2 moles) was added slowly over a period of 30 to $60 \mathrm{~min}$. The progress of the reaction was determined by the disappearance of the solid sodium ethoxide.

After the ketone had been added, the mixture was stirred for $3 \mathrm{hr}$ in the ice bath, allowed to stand overnight at room temperature, recooled in an ice bath, and diluted with an equal volume (or more) of cold water to dissolve the solid that had precipitated. After separation of the resulting layers, the aqueous layer was washed with four $100-\mathrm{ml}$ portions of ether, and the toluene layer was extracted with four $100-\mathrm{ml}$ portions of water. The aqueous layer and washings were combined and acidified with $130 \mathrm{ml}(65 \mathrm{ml}$ per mole of sodium ethoxide used) of glacial acetic acid, yielding the ketone as the upper, oily layer. This layer was separated, and the lower aqueous layer was extracted with four $100-\mathrm{ml}$ portions of ether. The diketone and the ether extracts were combined, washed successively with three $50-\mathrm{ml}$ portions of water and three $50-\mathrm{ml}$ portions of a saturated solution of sodium bicarbonate, and dried with calcium chloride. The ether was removed by evaporation. and the ketone was fractionally distilled under diminished pressure; yicld, $171 \mathrm{~g}$ (60 percent), bp, $71-76^{\circ} \mathrm{C}(18 \mathrm{~mm})$.

\subsection{Preparation of Compounds Chosen as Standards}

Table 6 lists the compounds selected as standards, together with their formulas, molecular weights, and results of analysis for the pertinent element in each.

5 This compound may now bo purchased from Chemicals Procurement Laboratories, Inc., College Point, N.Y. 
TABLE 6. Formulas, molecular weights, and analyses of compounds chosen as standard samples

\begin{tabular}{|c|c|c|c|c|c|c|c|}
\hline \multirow{2}{*}{$\begin{array}{l}\text { Serial } \\
\text { No. }\end{array}$} & \multirow{2}{*}{$\begin{array}{l}\text { NBS Standard } \\
\text { Sample No. }\end{array}$} & \multirow{2}{*}{ Compound } & \multirow{2}{*}{ Formula } & \multirow{2}{*}{$\begin{array}{l}\text { Molecular } \\
\text { weight }\end{array}$} & \multicolumn{3}{|c|}{ Elcment } \\
\hline & & & & & Symbol & Calculated & Found $s$ \\
\hline & & Cyclohexanebutyrate & & & & $\%$ & $\%$ \\
\hline$\frac{1}{2}$ & $1050--$ & $\begin{array}{l}\text { Aluminum } \\
\text { Barium }\end{array}$ & $\begin{array}{l}\mathrm{C}_{20} \mathrm{H}_{35} \mathrm{AlO}_{5} \\
\mathrm{C}_{20} \mathrm{H}_{34} \mathrm{BaO}_{4}\end{array}$ & $\begin{array}{l}382.45 \\
475.82\end{array}$ & 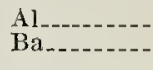 & $\begin{array}{r}7.05 \\
28.87\end{array}$ & $\begin{array}{r}6.9 \\
28.1\end{array}$ \\
\hline $\begin{array}{l}3 \\
4\end{array}$ & $\begin{array}{l}1053- \\
1054--\end{array}$ & $\begin{array}{l}\text { Cadmium } \\
\text { Calcium }\end{array}$ & $\begin{array}{l}\mathrm{C}_{20} \mathrm{H}_{34} \mathrm{CdO} \\
\mathrm{C}_{20} \mathrm{H}_{34} \mathrm{CaO}\end{array}$ & $\begin{array}{l}450.87 \\
378.54\end{array}$ & 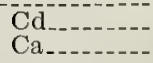 & $\begin{array}{l}24.93 \\
\text { 10. } 59\end{array}$ & $\begin{array}{l}23.9 \\
10.5\end{array}$ \\
\hline 5 & 1055 & Cobalt (ous) & b unknown & - & $\mathrm{Co}$ & & 17.1 \\
\hline 6 & 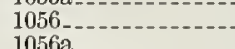 & Copper (ic) & $\mathrm{C}_{20} \mathrm{H}_{34} \mathrm{CuO}_{4}$ & 402.00 & $\mathrm{Cu}$ & 15.81 & 16. 0 \\
\hline 7 & 1058 & Iron & o unknown & & $\mathrm{Fe}_{-}$ & - & 19.3 \\
\hline 8 & 1059 & Lead_...-. & $\mathrm{C}_{20} \amalg_{34} \mathrm{O}_{4} \mathrm{~Pb}$ & 545.67 & $\mathrm{~Pb}_{-}$ & 37.97 & 37.5 \\
\hline 9 & $\begin{array}{l}1060- \\
1060 a\end{array}$ & Lithium & $\mathrm{C}_{10} \mathrm{H}_{17} \mathrm{LiO}{ }_{2}$ & 176.17 & $\mathrm{Li}_{---}$ & 3.94 & $\begin{array}{l}4.0 \\
4.1\end{array}$ \\
\hline 10 & $1061-\ldots$ & Magnesium... & $\mathrm{C}_{20} \mathrm{I}_{34} \mathrm{MgO}_{4}$ & 362.78 & $\mathrm{Mg}_{-}$ & 6.70 & $\begin{array}{l}\text { 6.1 } \\
6.9 \\
6.8\end{array}$ \\
\hline 11 & 1062 & Mangancsc (ous) & $\mathrm{C}_{20} \mathrm{H}_{34} \mathrm{MnO}_{4}$ & 393.40 & $\mathrm{Mn}$ & 13.97 & 13. 9 \\
\hline $\begin{array}{l}12 \\
13\end{array}$ & 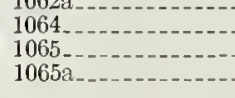 & $\begin{array}{l}\text { Merury (ic) } \\
\text { Nickel (ous) }\end{array}$ & $\begin{array}{l}\mathrm{C}_{20} \mathrm{H}_{34} \mathrm{HgO}_{4} \\
\text { d unknown }\end{array}$ & 539.07 & $\begin{array}{ll}\mathrm{H} g \\
\mathrm{Ni}--.\end{array}$ & 37.21 & $\begin{array}{l}3.8 \\
36.2 \\
17.6 \\
16.8\end{array}$ \\
\hline $\begin{array}{l}14 \\
15 \\
16\end{array}$ & $\begin{array}{l}1067--- \\
1068--- \\
1069--- \\
1069 a_{---}\end{array}$ & 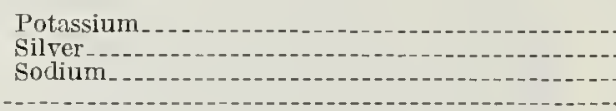 & $\begin{array}{l}\mathrm{C}_{10} \mathrm{H}_{17} \mathrm{KO}_{2} \\
\mathrm{C}_{10} \mathrm{H}_{17} \mathrm{AgO}_{2} \\
\mathrm{C}_{10} \mathrm{H}_{17} \mathrm{NaO}_{2}\end{array}$ & $\begin{array}{l}208.33 \\
277.11 \\
192.22 \\
-.--.-\end{array}$ & 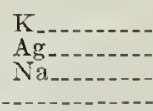 & $\begin{array}{l}18.77 \\
38.93 \\
11.96\end{array}$ & $\begin{array}{l}19.0 \\
38.7 \\
12.0 \\
11.9\end{array}$ \\
\hline 17 & $\begin{array}{l}1070 \ldots \\
1070 \mathrm{a}_{-.}\end{array}$ & Strontium & $\mathrm{C}_{20} \mathrm{I}_{34} \mathrm{O}_{4 \mathrm{SS}} \cdot 1.5 \mathrm{H}_{2} \mathrm{O}$ & 453.15 & $\mathrm{Sr}_{--}$ & 19.34 & $\begin{array}{l}19.8 \\
20.7\end{array}$ \\
\hline 18 & $\begin{array}{l}1073-\ldots- \\
1073 a_{-\ldots-}\end{array}$ & Zine_-..-- & $\mathrm{C}_{20} \mathrm{I}_{34} \mathrm{O}_{4} \mathrm{Zn}$ & 403.84 & $\begin{array}{l}\mathrm{Zn}_{\mathrm{n}}-\ldots-. \\
\mathrm{Zn}_{-.-.}\end{array}$ & 16.19 & $\begin{array}{l}18.5 \\
16.7\end{array}$ \\
\hline & & Miscellaneous & & & & & \\
\hline 19 & $\begin{array}{l}1063 . \\
1063 \mathrm{a}\end{array}$ & Menthyl borate & $\mathrm{C}_{30} \mathrm{H}_{57} \mathrm{BO}_{3}$ & 476.58 & $B_{--}$ & 2.27 & $\begin{array}{l}2.27 \\
2.4\end{array}$ \\
\hline 20 & $1072-.--$ & Tris $\left(2^{\prime}\right.$-hydroxyacetophenono)-chromim(111) & $\mathrm{C}_{24} \mathrm{I}_{21} \mathrm{CrO}_{6}$ & 457.41 & $\mathrm{Cr}$ & 11.37 & 10.6 \\
\hline 21 & 1071 & Triphenyl phosphate & $\mathrm{C}_{18} \Pi_{15} \mathrm{O}_{4} \mathrm{P}$ & 326.28 & P....... & 9. 49 & 9.5 \\
\hline $\begin{array}{l}22 \\
23\end{array}$ & $\begin{array}{l}1066-- \\
1057--\end{array}$ & $\begin{array}{l}\text { Octaphenyleyclotetrasiloxane } \\
\text { Dibutyltin bis(2-ethylhexanoate)--. }\end{array}$ & $\begin{array}{l}\mathrm{C}_{48} \\
\mathrm{C}_{24} \mathrm{H}_{48} \mathrm{O}_{4} \mathrm{Sn}\end{array}$ & $\begin{array}{l}793.21 \\
519.34\end{array}$ & Sin-.. & 22.86 & $\begin{array}{l}14.1 \\
23.6\end{array}$ \\
\hline 24 & $\begin{array}{l}1052 \ldots \\
1052 a- \\
1052 a-1\end{array}$ & Bis(1-phenyl-1,3-butanediono) oxovanadium(IV) & $\mathrm{C}_{20} \mathrm{I}_{18} \mathrm{O}_{5} \mathrm{~V}$ & 389.29 & $v_{--}^{--}$ & 13.09 & $\begin{array}{l}13.1 \\
13.1\end{array}$ \\
\hline 25 & $1074-$ & Calcium 2-ethylhexanoate.-. & í unknown & & $\mathrm{Ca}$ & & 13.4 \\
\hline $\begin{array}{l}26 \\
27 \\
28\end{array}$ & 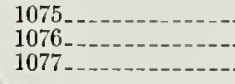 & $\begin{array}{l}\text { Aluminum 2-ethylhexanoatc- } \\
\text { Potassium erucate- } \\
\text { Silver 2-ethylhexanoate- }\end{array}$ & $\begin{array}{l}\mathrm{C}_{16} \mathrm{H}_{31} \mathrm{AlO}_{5} \\
\mathrm{C}_{22} \mathrm{H}_{41} \mathrm{KO}_{2} \\
\mathrm{C}_{8} \mathrm{H}_{15} \mathrm{AgOO}_{2}\end{array}$ & $\begin{array}{l}330.41 \\
376.67 \\
251.09\end{array}$ & 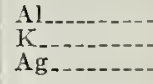 & $\begin{array}{r}8.17 \\
10.38 \\
42.96\end{array}$ & $\begin{array}{r}7.5 \\
10.1 \\
42.4\end{array}$ \\
\hline
\end{tabular}

a By analysis of the compound dried at $25^{\circ}$ over phosphorus pentaoxide iu a desiccator.

b Calculated for $\mathrm{C}_{20} \mathrm{H}_{34} \mathrm{CoO}_{4}(\mathrm{M} . \mathrm{W} ., 397.40)$ : $\mathrm{Co}, 14.83$.

c Calculated for $\mathrm{C}_{10} \mathrm{H}_{17} \mathrm{O}_{2} \mathrm{Fe}(\mathrm{OH})_{2}$ (M. $\mathrm{M}$. . 259.11$)$ : $\mathrm{Fe}, 21.55$.

d Calculated for $\mathrm{C}_{20} \mathrm{H}_{34} \mathrm{NiO}_{4}(\mathrm{M}$. W., 397.17): $\mathrm{Ni}, 14.78$.

- Calculated for $\mathrm{C}_{20} \mathrm{H}_{34} \mathrm{O}_{4} \mathrm{Zn}$ (M.W., 403.84$): \mathrm{Zn}, 16.19$.

f Calculated for $\mathrm{C}_{10} \mathrm{H}_{30} \mathrm{CaO}$ (M.W., 326.50$): \mathrm{Ca}, 10.82$,

\subsubsection{Cyclohexanebutyrates}

a. Preparation

Table 7 gives a summary of the compounds used in the preparation of the cyclohexanebutyrates and the yields of the respective, purified products.

Aluminum cyclohexanebutyrate (table 6, compound 1) was prepared by the reaction of cyclohexanebutyric acid with aluminum isopropoxide in boiling toluene.

Seven other cyclohexanebutyrates (compounds $5,7,9,13,14,16$, and 18) were prepared from the free acid (method a). Absolute ethanol (2 liters) was placed in a large Pyrex beaker equipped with an induction-type, electric stirrer, $340.5 \mathrm{~g}$ (2 moles) of cyclohexanebutyric acid was added, and the mixture was stirred until all of the acid had dissolved. In some preparations (see table
7), the solution was now heated to 70 to $75^{\circ} \mathrm{C}$ on the steam bath. For all salts except that of ron (see detailed description), an aqueous solution of the metal compound (see table 7) at the prescribed temperature was then added dropwise, with stirring, and the preparation was continued as described in the individual descriptions.

This general method was later improved by first converting the cyclohexanebutyric acid to the sodium salt (method b), and this procedure was employed for preparation of the other cyclohexanebutyrates (compounds $2,3,4,6,8,10,11,12,15$, and 17). Sodium hydroxide ( $81.6 \mathrm{~g}$ of 98 percent; 2.0 moles) was placed in a large Pyrex beaker (equipped with an electric stirrer and 1-liter dropping funnel) and 2 liters of water was added, with stirring. Into the resulting solution was rapidly poured, with stirring, $340.5 \mathrm{~g}$ (2.0 
TABLE 7. Experimental details in the preparation of cyclohexanebutyrates

\begin{tabular}{|c|c|c|c|c|c|c|c|c|c|}
\hline \multicolumn{4}{|c|}{ Starting material } & \multirow{2}{*}{$\begin{array}{l}\text { Water } \\
\text { used }\end{array}$} & \multirow{2}{*}{ Temp. b } & \multicolumn{3}{|c|}{ Yield of pure product } & \multirow{2}{*}{$\begin{array}{c}\text { Serial } \\
\text { No. of } \\
\text { product }\end{array}$} \\
\hline Formula & Mol. wt. & Amol & used & & & Calcu- & & & \\
\hline $\mathrm{Al}\left(\mathrm{OC}_{3} \mathrm{H}_{7}\right)_{3}$ & 2043 & $g \mathrm{~s}$ & moles & liters & ${ }^{\circ} C$ & 25 & $q$ & $\%$ & \\
\hline $\mathrm{Ba}(\mathrm{OAc})_{2}{ }^{3}$ & 255.5 & $\begin{array}{l}136.2 \\
268.3\end{array}$ & $\begin{array}{l}0.00 \\
1.05\end{array}$ & $\begin{array}{l}0.0 \\
2.0\end{array}$ & $60-70$ & $\begin{array}{l}253 \\
475.8\end{array}$ & $\begin{array}{l}249 \\
333\end{array}$ & $\begin{array}{l}96 \\
70\end{array}$ & $\frac{1}{2}$ \\
\hline $\mathrm{Cd}\left(\mathrm{NO}_{3}\right)_{2} \cdot 4 \mathrm{H}_{2} \mathrm{O}$ & 308.5 & 308.5 & 1.0 & 1.3 & 25 & 450.9 & 334 & 74 & 3 \\
\hline $\mathrm{Ca}(\mathrm{OAC})_{2} \cdot \mathrm{H}_{2} \mathrm{O}$ & 176.2 & 185.2 & 1.05 & 1.9 & 25 & 378.5 & 295 & 78 & 4 \\
\hline $\mathrm{Co}(\mathrm{OAC})_{2} \cdot 4 \mathrm{H}_{2} \mathrm{O}$ & 249.1 & 261.6 & 1.05 & 1.8 & $70-75$ & & 270 & & 5 \\
\hline $\mathrm{CuSO}_{4} \cdot 5 \mathrm{H}_{2} \mathrm{O}$ & 249.7 & 262.2 & 1.05 & 2.3 & 25 & 402.0 & 368 & 91 & 6 \\
\hline $\mathrm{FeCl}_{3} \cdot 6 \mathrm{H}_{2} \mathrm{O}$ & 270.3 & 180.2 & 0.66 & 0.5 & $70-75$ & & 134 & & 7 \\
\hline $\mathrm{Pb}(\mathrm{OAc})_{2} \cdot 3 \mathrm{H}_{2} \mathrm{O}$ & 379.4 & 417.3 & 1. 1 & 2.0 & $60-70$ & 545.7 & 463 & 85 & 8 \\
\hline $\mathrm{LiOH} \cdot \mathrm{H}_{2} \mathrm{O}$ & 41.96 & 83.9 & 2.0 & 0.965 & 25 & 352.3 & 314 & 89 & 9 \\
\hline $\mathrm{Mg}(\mathrm{OAc})_{2} \cdot 4 \mathrm{H}_{2} \mathrm{O}$ & 214.5 & 214.5 & 1.0 & 0.5 & 25 & 362.8 & 287 & 79 & 10 \\
\hline $\mathrm{MnCl}_{2} \cdot 4 \mathrm{H}_{2} \mathrm{O}$ & 197.9 & 197.9 & 1.0 & 1.0 & 25 & 393.4 & 315 & 80 & 11 \\
\hline $\mathrm{Hg}(\mathrm{OAC})_{2}$ & 318.7 & 334.6 & 1.05 & 2.0 & 25 & 539.1 & 380 & 70 & 12 \\
\hline $\mathrm{Ni}(\mathrm{OAc})_{2} \cdot 4 \mathrm{H}_{2} \mathrm{O}$ & 248.9 & 261.4 & 1.05 & 2.5 & $70-75$ & & 312 & & 13 \\
\hline $\mathrm{KOH}$ & 56.1 & - 132.0 & 2.0 & 0.449 & 25 & 416.6 & 358 & 86 & 14 \\
\hline $\mathrm{AgNO}_{3}$ & 169.9 & 356.8 & 2.1 & 6.0 & 25 & 554.2 & 520 & 94 & 15 \\
\hline $\mathrm{NaOH}$ & 40.0 & d 81.6 & 2.0 & 0.72 & 25 & 384.5 & 322 & 84 & 16 \\
\hline $\mathrm{SrCl}_{2} \cdot 6 \mathrm{H}_{2} \mathrm{O}$ & 266.6 & 266.6 & 1.0 & 0.5 & 25 & 453.2 & 354 & 78 & 17 \\
\hline $\mathrm{Zn}(\mathrm{OAc})_{2} \cdot 2 \mathrm{H}_{2} \mathrm{O}$ & 219.5 & 219.5 & 1.0 & 2.0 & 25 & & 355 & & 18 \\
\hline
\end{tabular}

a Per 2.0 moles $(340.5 \mathrm{~g})$ of cyclohexanebutyric acid.

b Of reaction and, unless otherwise noted, of the aqueous solution.

- Of 85 percent.
d Of 98 percent.

moles) of warm, molten cyclohexanebutyric acid, and the mixture was stirred until an essentially clear solution resulted (4 $\mathrm{min})$. In some preparations (see table 7 ), the solution was now heated to 65 to $70^{\circ}$ on the steam bath. An aqueous solution of the metal compound (see table 7) at the prescribed temperature was then added dropwise, with stirring, usually during 20 to $30 \mathrm{~min}$, and the preparation was continued as described in the individual descriptions.

(1) Aluminum cyclohexanebutyrate. Aluminum isopropoxide (204.3 g, 1 mole), cyclohexanebutyric acid $(512.4 \mathrm{~g}, 3.01$ moles), and 1 liter of toluene were placed in a 3-liter, 2-necked, roundbottomed flask fitted with a 1-liter dropping funnel (filled with toluene) and with a reflux condenser to the top of which was attached a connecting tube equipped with a thermometer and a water-cooled condenser set for distillation. The mixture was refluxed for $1 \mathrm{hr}$; the flow of water through the reflux condenser was then stopped and the water was drained out, she temperature of the heater was regulated to give a reflux ratio of about 1:7, and the stopcoek of the dropping funnel was earefully opened and so adjusted that the number of drops of toluene entering the flask equaled the number of drops of distillate colleeted. During $3 \mathrm{hr}$, the vapor temperature rose from 80 to $88^{\circ}$ and $400 \mathrm{ml}$ of distillate was collected; during a total time of $5 \mathrm{hr}$, the temperature rose to $110^{\circ}$ and $900 \mathrm{ml}$ of distillate was eollected (and discarded).

The hot solution was filtered through toluenewashed, filter-paper pulp, and the filtrate was cooled to room temperature, transferred to a 6-liter, Pyrex jar, and vigorously stirred while 4 liters of acetone was gradually added, producing a turbid solution. Stirring of the solution was eontinued during $30 \mathrm{~min}$, while 1 liter of acetone containing $18 \mathrm{~g}$ of water was added, precipitating a white, spongy produet. The mixcure was refrigerated overnight, and the preeipitate was collected on a Büchner funnel, washed with acetone, and dried and powdered in the usual way.

(2) Barium cyclohexanebutyrate. By use of method $b$ and the quantities of reactants given in table 7, a sticky, soft precipitate resulted. After the mixture had been stirred for about $30 \mathrm{~min}$ at 60 to $70{ }^{\circ} \mathrm{C}$, the solution was decanted from the preeipitate and disearded; the precipitate was washed successively with four $300-\mathrm{ml}$ portions of water at 60 to $70{ }^{\circ} \mathrm{C}$, and two $300-\mathrm{ml}$ quantities of absolute ethanol at $25^{\circ} \mathrm{C}$, and then stirred with $500 \mathrm{ml}$ of acetone for $30 \mathrm{~min}$, during which time the precipitate beeame hard and granular. The solid was collected on a Büchner funnel, air dried, and dissolved in a hot solution of $600 \mathrm{ml}$ of methanol and $50 \mathrm{ml}$ of water in 2.5 liters of butyl aeetate. The hot, clear solution was filtered transferred to a 4-liter beaker (placed on a cork mat and equipped with a stirrer), and allowed to cool while being rapidly stirred. After the solution had been stirred for about $30 \mathrm{~min}$, the barium salt began to separate as a finely divided preeipitate; when the temperature of the solution had reached about $25^{\circ} \mathrm{C}$, the preeipitate was collected by suction filtration. The filtrate was refrigerated overnight, affording a second batch of precipitate which was colleeted, combined with the first batch, and air dried. A second purification of the salt was earried out by redissolving in the butyl acetate-metlanol-water mixture and cooling, alter which the salt was collected on a Büchmer funnel, and dried and powdered as usual.

(3) Cadmium cyclohexanebutyrate. To a solution of the acid (see table 7) in $667 \mathrm{ml}$ of absolute ethanol was added a solution of the sodium liydroxide (see method b) in $667 \mathrm{ml}$ of water, followed by the solution of cadnium nitrate; a white preeipitate was obtained. After being stirred for a further 30 min; the mixture was filtered by 
suction, and the precipitate was washed by stirring with water, refiltering, and repeating the process twice. The moist precipitate was added to boiling absolute methanol (in the ratio of $500 \mathrm{~g}$ of precipitate to 2 liters of methanol) and the resulting suspension was filtered. The insoluble precipitate remaining was dissolved by suspending it in hot methanol and adding, with stirring, sufficient cyclohexanebutyric acid to give complete dissolution. The two solutions were combined, water was added to turbidity, and the solution was refrigerated, giving a precipitate which was removed with suction. The product was recrystallized as previously described, but excess water was added to the heated solution whenever an oil (instead of crystals) settled out on refrigeration. The product was filtered off, and dried and powdered in the usual way.

Analysis. Calculated for $\mathrm{C}_{20} \mathrm{H}_{34} \mathrm{CdO}_{4}$ : C, 53.28; H, 7.6. Found: C, 53.35; H, 7.7.

(4) Calcium cyclohexanebutyrate. The calcium acetate solution (see table 7 ) was added to a solution of the sodium cyclohexanebutyrate (see method b) in $700 \mathrm{ml}$ of water plus $700 \mathrm{ml}$ of absolute ethanol; a white precipitate was formed. The mixture was refrigerated overnight; the precipitate was then collected in a Büchner funnel, transferred to a 4-liter beaker (equipped with a stirrer), and washed by stirring with several $200-\mathrm{ml}$ portions of water. The solid was collected by suction filtration, air dried, crushed, and dried over phosphorus pentaoxide; weight, $372 \mathrm{~g}$. 'The dry salt (372 g) was dissolved, with stirring, in a sufficiency of $43: 57(\mathrm{vol} / \mathrm{vol})$ aqueous ethanol at 70 to $75{ }^{\circ} \mathrm{C}$ on the steam bath, filtered, cooled to $25{ }^{\circ} \mathrm{C}$, and refrigerated overnight. The salt separated as short, needlelike crystals which were collected by suction filtration and washed with water. The salt was recrystallized once by the same procedure, and dried and powdered as usual.

(5) Cobalt cyclohexanebutyrate. By use of method a and the quantities of reactants given in table 7 , a soft, lavender precipitate was obtained. After the mixture had been stirred for about 30 min at 65 to $70{ }^{\circ} \mathrm{C}$, the supernatant solution was decanted and discarded, and the precipitate was stirred with $500 \mathrm{ml}$ of acetone for $20 \mathrm{minl}$, during which time the precipitate solidified. The solid was collected by suction filtration, washed successively with water and acetone, and dissolved at 60 to $70^{\circ}$ in 1.5 liters of $1: 1$ ( $\mathrm{vol} / \mathrm{vol}$ ) methanolbutyl acetate. The hot solution was filtered through absorbent cotton, cooled to $45{ }^{\circ} \mathrm{C}$, stirred while acetone was added dropwise to incipient turbidity, cooled to $25^{\circ} \mathrm{C}$, and refrigerated. The salt separated as a finely divided precipitate which was collected on a Büchner funnel, washed with absolute ethanol, air dried, repurified (by the same procedure) from 1.2 liters of $1: 1$ (vol/vol) methanol-butyl acetate, and dried and powdered as usual.

(6) Copper cyclohexanebutyrate. A solution of the sodium cyclohexanebutyrate (see method b) in 4 liters of water plus 1 liter of absolute ethanol was added dropwise to the solution of copper sulfate (see table 7); a finely divided, blue precipitate resulted. The mixture was kept at $25^{\circ} \mathrm{C}$ overnight; the precipitate was then collected by suction filtration, transferred to a 4-liter beaker equipped with a stirrer, and washed successively, with stirring, with three $300-\mathrm{ml}$ portions of water, two 300-ml quantities of 50-percent ( $\mathrm{vol} / \mathrm{vol}$ ) aqueous ethanol, and $500 \mathrm{ml}$ of acetone (for 20 min). The solid was collected on a Büchner funnel, air dried, powdered, sieved (20-mesh), and dried over phosphorus pentaoxide at $2 \mathrm{~mm}$; weight, $398 \mathrm{~g}$ The copper cyclohexanebutyrate (398 g) was dissolved, with stirring, in 1 liter of absolute ethanol at 65 to $70^{\circ} \mathrm{C}$ on the steam bath. The hot, blue solution was filtered through filter-paper pulp, and the filtrate was cooled to room temperature and refrigerated. After the solution had been refrigerated for 3 days (with intermittent scratching of the sides of the flask and warming of the solution to $25^{\circ} \mathrm{C}$ ), the copper salt precipitated from solution. A second purification of the salt was carried out by redissolving the precipitate in 1 liter of absolute ethanol, refrigerating, and nucleating the solution. The salt was collected on a Büchner funnel, and dried and powdered in the usual way.

(7) Iron cyclohexanebutyrate. To a solution of the acid (see table 7) in $333 \mathrm{nnl}$ of absolute ethanol at $25{ }^{\circ} \mathrm{C}$ was added $134 \mathrm{ml}$ of concentrated ammonium hydroxide (sp gr 0.90) and then, with vigorous stirring, the hot solution of ferric chloride. A red-brown oil was precipitated. The supernatant liquor was decanted and set aside, and the oil was transferred to a 2 -liter separatory funnel, washed with four 200-ml portions of hot water (70 to $80{ }^{\circ} \mathrm{C}$ ), filtered twice (with difficulty) through absorbent cotton, and transferred to a 4liter beaker equipped with a stirrer. Aqueous acetone (2 liters of 10 -percent) was gradually added during $30 \mathrm{~min}$, with the formation of a brown granular precipitate which was dissolved in a solution of $13.5 \mathrm{ml}$ of cyclohexanebutyric acid in $667 \mathrm{ml}$ of chloroform and vigorously stirred while 2.7 liters of acetone was added dropwise during $50 \mathrm{~min}$. The solid was collected on a Büchner funnel, washed successively with absolute ethanol and acetone, and dried and powdered as usual. [The filtrate was concentrated and unreacted cyclohexanebutyric acid (213 g, 1.25 moles) was recovered (see section 3.4.1.b).]

(8) Lead cyclohexanebutyrate. The hot solution of lead acetate (see table 7) was added to a hot solution of the sodium cyclohexanebutyrate (see method b) in 1.5 liters of water plus 1 liter of absolute ethanol, and a sticky, soft precipitate was produced. The mixture was diluted with 2 liters of water and stirred for $2 \mathrm{hr}$, during which time the precipitate solidified. The white salt was collected by suction filtration, transferred to a 4liter beaker, washed successively with three $300-\mathrm{ml}$ portions of water at 60 to $70{ }^{\circ} \mathrm{C}$ and two $300-\mathrm{ml}$ quantities of absolute ethanol, and dissolved in 7 
liters of butyl acetate at 70 to $80{ }^{\circ} \mathrm{C}$. The hot solution was filtered twice, by suction, through filter-paper pulp on ordinary filter paper, placed in a 10-liter, cylindrical, Pyrex jar, and vigorously stirred while 3 liters of a $2: 1$ ( $\mathrm{vol} / \mathrm{vol}$ ) solution of acetone in butyl acetate was slowly added.

After the solution had been stirred for about 10 min, the lead salt began to separate as a stringy precipitate, and, after about a further $30 \mathrm{~min}$, the suspension became a gel which was too viscous to be stirred. The mass was transferred to a large Büchner funnel, pressed free of most of the butyl acetate, washed with absolute ethanol, and air dried. In like manner, the filtrate (not mixed with the ethanol washings) was stirred until the solution gelled; the butyl acetate solution was pressed out of the precipitate and refrigerated, yielding more precipitate. The precipitates wcre combined, washed with absolute ethanol, air dried, redissolved in butyl acetate, collected by the same procedure, and dried and pulverized as usual; mp $85-86{ }^{\circ} \mathrm{C}$.

(9) Lithium cyclohexanebutyrate. Use of method $a$ and the quantities of reactants given in table 7 gave a solution. The solution was evaporated to $700 \mathrm{ml}$ on the steam bath, and butyl acetate (2 liters) was added to the mixture, which was then heated slowly to 95 to $105{ }^{\circ} \mathrm{C}$ until most of the water had evaporated, giving a slightly turbid solution. Sufficient water was added to remove the turbidity, and the mixture was filtered. The filtrate was allowed to cool to room temperature, nucleated, and refrigerated overnight, giving a precipitate which was filtered off with suction and dispersed in 2 liters of butyl acetate. The suspension was heated slowly, with occasional addition of a little water, until the solution showed a slight turbidity at $95^{\circ} \mathrm{C}$. A slight excess of water was added to remove the turbidity, and the clear solution was filtered, cooled, and refrigerated, giving a precipitate which was filtered with suction, washed twice with acetone, and dried and powdered as usual.

(10) Magnesium cyclohexanebutyrate. By use of method $b$ and the quantities of reactants given in table 7, a white precipitate was formed. After being stirred for a further $30 \mathrm{~min}$, the mixture was refrigerated overnight. With the aid of a filter-flask containing several $\mathrm{ml}$ of butyl acetate (to decrease foaming), the mixture was filtered by suction; the filtrate was refrigerated for 3 to $4 \mathrm{hr}$ (to give a second crop of white precipitate) and refiltered. The precipitates were combined and were washed by stirring with water, refiltering, and repeating the treatment twice.

Butyl acetate (1 liter) was now added to the moist precipitate, and the suspension was slowly heated to 85 to $93{ }^{\circ} \mathrm{C}$ and maintained at that temperature until dissolution was complete. (At this point, the solution was often slightly turbid and was boiling gently.) The solution was filtered into a 4-liter beaker, stirred, nucleated, and allowed to cool to room temperature, affording a white precipitate. After the mixture had been refrigerated overnight, the precipitate was filtered off with suction, again recrystallized from 1 liter of butyl acetate, as before, and dried and powdered as usual.

(11) Manganese cyclohexanebutyrate. The solution of sodium cyclohexanebutyrate (see metlod b) was added to the solution of manganous chloride (see table 7) during $90 \mathrm{~min}$. After being stirred for a further $30 \mathrm{~min}$, the mixture was refrigerated overnight. The suspension was filtered by suction and the precipitate was twice stirred with water and refiltered. The moist product (ca. 2,000 g) was purified as follows. To an aliquot $(500 \mathrm{~g})$ was added $143.5 \mathrm{ml}$ of absolute methanol followed by $1,092.5 \mathrm{ml}$ of chloroform, and the suspension was stirred until most of the salt had dissolved. Butyl acetate $(1,316 \mathrm{ml})$ was now added and the mixture was stirred until dissolution was complete. The solution was filtered, and to the clear filtrate was added $865.5 \mathrm{ml}$ of butyl acetate, followed by $108.5 \mathrm{ml}$ of water. The resulting solution was shaken, nucleated, and refrigerated $\left(-5{ }^{\circ} \mathrm{C}\right)$ overnight. The resulting precipitate was filtered off with suction, washed by stirring with acetone and refiltering, and dried and powdered in the usual way.

(12) Mercuric cyclohexanebutyrate. The mercuric acetate solution (see table 7) was added to a solution of the sodium cyclohexanebutrate (see method b) in 1.5 liters of water plus 1 liter of absolute ethanol, giving a milky-white suspension; from this, a very small quantity of heavy oil separated. After the mixture had been stirred for about $15 \mathrm{~min}$, the suspension was refrigerated overnight, giving off-white, sticky crystals which were collected by suction filtration, washed successively (in a 2-liter beaker) with two 200-ml quantities of ice water and one 100-ml portion of absolute ethanol, filtered, and air dried. The crystals were carefully added portionwise to 1.5 liters of vigorously stirred, hot $\left(65\right.$ to $\left.70{ }^{\circ} \mathrm{C}\right)$ absolute ethanol containing $20 \mathrm{~g}$ of cyclohexanebutyric acid in a 4-liter beaker on the steam bath, and stirring was continued for an additional 5 min, during which time most of the salt dissolved, leaving a deep-orange, insoluble material that was removed eompletely by three rapid filtrations, with suction, through a layer of filter-paper pulp placed on ordinary filter paper.

The clear filtrate was transferred to a 4-liter beaker equipped with a stirrer, and 40 to $60 \mathrm{ml}$ of water was gradually added, with stirring, to give a faintly turbid solution which was refrigerated overnight. The salt separated as clumps of crystals which were collected by suction filtration, washed with cold absolute ethanol, air dried, recrystallized (by the same procedure) from 1.1 liters of absolute ethanol, and dried and powdered as usual; mp, $75.5-76.5^{\circ} \mathrm{C}$.

(13) Nickel cyclohexanebutyrate. By use of method a and the quantities of reactants given in table 7 , a viscous, green oil was precipitated. 
After the mixture had been stirred for about 30 min at 65 to $70{ }^{\circ} \mathrm{C}$, the supernatant liquor was decanted, and the oil was dissolved in $750 \mathrm{ml}$ of chloroform, transferred to a 3-liter separatory funnel, washed three times with 200-ml portions of water, and filtered twice through absorbent cotton on ordinary filter paper. 'The clear, green solution was added dropwise, with stirring, to 4 liters of absolute ethanol in a 6-liter cylindrical jar. The salt separated as a finely divided, lightgreen precipitate which was collected by suction filtration, washed with hot $\left(70{ }^{\circ} \mathrm{C}\right), 10$-percent (vol/vol) aqueous ethanol, and air dried. The dry product was dissolved in 1 liter of butyl acetate containing $10 \mathrm{~g}$ of cyclohexanebutyric acid, diluted dropwise with acetone to incipient turbidity, refrigerated, collected on a Büchncr funnel, and dried and powdered as usual.

(14) Potassium cyclohexanebutyrate. Using method a, 20-percent aqueous potassium hydroxide solution (see table 7) was added to a solution of the acid in $500 \mathrm{ml}$ of absolute ethanol (faint pink to phenolphthalein). The solution was transferred to a large evaporating dish, concentrated on the steam bath, with frequent stirring, to a volume of about $400 \mathrm{ml}$, and transferred to an 8-liter beaker equipped with a stirrer. The viscous solution was cooled to $40{ }^{\circ} \mathrm{C}$ and stirred, while 5 liters of acetone was added during $15 \mathrm{~min}$, with the formation of a bulky, white, granular precipitate. After the mixture had been stirred for $15 \mathrm{~min}$, the precipitate was collected on a Büchner funnel, washed with acetone, air dried, and mixed with 1.4 liters of 12-percent ethanolbutyl acetate at 60 to $70{ }^{\circ} \mathrm{C} ; 20$ to $28 \mathrm{ml}$ of water was added to afford a clear solution. The hot, clear solution was filtered, transferred to a 6-liter beaker, and stirred while enough acetone was added dropwise to form a turbid solution which was then refrigerated overnight.

The salt separated as a soft, soaplike precipitate which was collected by decantation of the supernatant liquor, and washed with $200-\mathrm{ml}$ portions of 5-percent ( $\mathrm{vol} / \mathrm{vol})$ ethanol-acetone until a finely divided solid was obtained. The filtrate was mixed with more acetone and refrigerated, affording more of the solid product. The precipitates were combined, washed with acetone, air dried, redissolved as before (with the same quantities of solvent), refrigerated, isolated, and dried and powered as usual.

(15) Silver cyclohexanebutyrate. The silver nitrate solution (see table 7) was added to a solution of the sodium cyclohcxanebutyrate (see method b) in 2 liters of water plus 2 liters of absolute ethanol, and a white precipitate was formed. The mixture was stirred for $30 \mathrm{~min}$; the precipitate was then collected on a large Büchner funnel, pressed free of much of the absorbed liquid, transferred to an 8-liter, cylindrical jar, and washed successively, with stirring, with five 1liter portions of water, three 1-liter quantities of ethyl alcohol, and 1 liter of acetone (for 15 min). The salt was collected on a Büchner funnel, and dried and powdered as usual.

The silver salt sometimes became dark brown during the preparation and, to remove this color, the following procedure was followed. A suspension of $260 \mathrm{~g}$ of dark-brown silver cyclohexanebutyrate in $300 \mathrm{ml}$ of 30 -pcrcent aqueous ethanol in a 4-liter beaker was vigorously stirred while a solution of $20 \mathrm{~g}$ of cyclohexanebutyric acid in $320 \mathrm{~g}$ of concentrated ammonium hydroxide (sp gr 0.90 ) was slowly added, with the dissolution of most of the solid and the formation of a deepamber solution. The mixture was filtered; the filtrate was mixed with $4 \mathrm{~g}$ of acid-and-waterwashed, decolorizing carbon in a 4-liter bcaker, heated on the steam bath for $30 \mathrm{~min}$, and filtered twice through filter-paper pulp on ordinary filter paper. Decolorizing carbon $(4 \mathrm{~g})$ was added to the filtrate and the process was repeatcd; the filtrate was then placed in an 8-liter, cylindrical jar (equipped with a stirrer), and stirred while a solution of $20 \mathrm{ml}$ of concentrated nitric acid (sp gr 1.42) and $350 \mathrm{ml}$ of glacial acetic acid in 2 liters of water was added during $45 \mathrm{~min}$, precipitating silver cyclohexanebutyrate as a bulky, off-white solid. The precipitate was collected on a Büchner funnel, washed with several 500-ml portions of water, pressed free of most of the wash liquid, and dried and powered as usual; salt recovered, $190 \mathrm{~g}$. This procedure was repeated, if necessary.

(16) Sodium cyclohexanebutyrate. Using method a, a 10-percent aqueous sodium hydroxide solution (carbonate-free; see table 7) was added to a solution of the acid in $500 \mathrm{ml}$ of absolute ethanol (faint pink to phenolphthalein). The solution was placed in a large evaporating dish and, with frequent stirring, was concentrated on the steam bath to a viscous paste to which 200 $\mathrm{ml}$ of $1: 1$ ( $\mathrm{vol} / \mathrm{vol}$ ) aqueous ethanol was added, giving a viscous solution. The solution was filtered into a 6-liter beaker equipped with a stirrer, and 1.6 to 2 litcrs of acetone was gradually added, with stirring, giving a faintly turbid solution which was immediately filtered; the filtrate was refrigerated overnight. The salt separated as long, thin, needlelike crystals which were collected by suction filtration and washed once with $400 \mathrm{ml}$ of $1: 3$ ( $\mathrm{vol} / \mathrm{vol}$ ) ethanol-acetone. A second crop of crystals (about $40 \mathrm{~g}$ ) was obtained by adding acetone to the filtrate to incipient turbidity and refrigerating the mixture. The salt was recrystallized once by the same procedure, collected, dried, and powdered as usual. During the drying, the crystallinity of the salt was lost.

(17) Strontium cyclohexanebutyrate hydrate. By use of method b and the quantities of reactants given in table 7 , a white precipitate was formed. After being stirred for a further $30 \mathrm{~min}$, the mixture was refrigerated overnight. 'The suspension was filtered by suction and the precipitate was washed by stirring with water, refiltering, and repeating the process twice. Butyl acetate (1 
liter) was now added to the moist precipitate, and the suspension was slowly heated to $93{ }^{\circ} \mathrm{C}$ and maintained at that temperature until dissolution was complete. (At this point, the solution was boiling.) The solution was filtered through a heated funnel into a 4-liter beaker, and the filtrate was stirred electrically. nucleated periodically, and allowed to cool to room temperature, affording a white precipitate. After the mixture had been refrigerated overnight, the precipitate was filtered off with suction, again recrystallized from 1 liter of butyl acetate, as before, and dried and powdered as usual.

Analysis. Calculated for $\mathrm{C}_{20} \mathrm{H}_{34} \mathrm{O}_{4} \mathrm{Sr} \cdot 1.5 \mathrm{H}_{2} \mathrm{O}$ : C, 53.01; H, 8.2. Found: C, 52.77; H, 8.1.

(18) Zinc cyclohexanebutyrate. Using method a, a solution of the acid (see table 7) in 1 liter of absolute ethanol was added to the solution of zinc acetate. A white precipitate was formed. After stirring for a further $30 \mathrm{~min}$, the suspension was filtered by suction and the precipitate was washed by stirring with 2 liters of water, refiltering, and repeating the treatment. Butyl acetate (1.334 liters) was now added to the moist precipitate, and the suspension was slowly heated to 70 to $80^{\circ} \mathrm{C}$ and maintained at that temperature until dissolution was complete. The solution was filtered, nucleated, and refrigerated overnight, giving a precipitate which was filtered off with suction, again recrystallized from 1.334 liters of butyl acetate, as before, and dried and powdered as usual.

\section{b. Recovery of Cyclohexanebutyric Acid}

A mixture of impure residues of salts of cyclohexanebutyric acid (crude solids and mother liquors) was placed in a porcelain evaporating dish on the steam bath and the solvents were evaporated. Excess aqueous 50-percent phosphoric acid was added, and the mixture was heated on the steam bath during $72 \mathrm{hr}$. The resulting aqueous suspension was diluted with water and the free acid was precipitated with ice. (Alternatively, it was extracted with chloroform, and the extract was washed with three portions of water. Decolorizing carbon was added to the washed chloroform layer, and the suspension was heated to boiling and filtered. The brown filtrate was transferred to a porcelain evaporating dish, and the chloroform and water were evaporated on the steam bath.) The resulting moist, crude cyclohexanebutyric acid was rapidly distilled at $3 \mathrm{~mm}\left(132-135^{\circ} \mathrm{C}\right)$, and the main fraction of distillate was redistilled twice, giving pure cyclohexanebutyric acid.

\subsubsection{Miscellaneous Compounds}

(19) DL-Menthyl borate. The method of preparation was essentially that described for $l$ menthyl borate [3]. A suspension of $61.8 \mathrm{~g}$ (1 mole) of boric acid in a solution of $468.9 \mathrm{~g}$ (3 moles) of DL-menthol in 2.6 liters of toluene (boiling stone) in a 6-liter, 1-necked, round-bottomed flask (equipped with a Barrett trap and a reflux con- denser) was boiled until the acid had dissolved $(15 \mathrm{~min})$ and for a further $2.75 \mathrm{hr} ; 53.4 \mathrm{ml}$ of water was collected in the trap (theoretical yield, $54.0 \mathrm{~g}$ ). The reaction mixture was allowed to cool to room temperature, and the reflux condenser and trap were replaced by a water-cooled condenser arranged for distillation. Two liters of toluene was distilled off and the remaining hot solution was filtered twice, by suction, and refrigerated, yielding $458 \mathrm{~g}$ (dry) of colorless crystals. This material was recrystallized twice from 1.5 liters of a $1: 1$ ( $\mathrm{vol} / \mathrm{vol}$ ) solution of acetone in ethyl acetate, and dried and powdered as usual; weight, $434 \mathrm{~g}$ (91 percent), mp, $151-152^{\circ} \mathrm{C}$.

(20) Tris ( $2^{\prime}-h y d r o x y a c e t o$ phenono) chromium (III). 2'-Hydroxyacctophenone (1361.4 g, 10 moles) was dissolved in 2 liters of absolute ethanol in a 4-liter beaker equipped with a stirrer, and vigorously stirred while $900 \mathrm{~g}$ of concentrated ammonium hydroxide (sp gr 0.90) was slowly added. The resulting pale-amber solution was stirred while a solution of $954 \mathrm{~g}$ of a commercial chromic acetate hydrate (corresponding to 3.0 moles of anhydrous acetate) in 3 liters of water was added, with the formation of a purplish-red solution; this solution was placed in an 8-liter, cylindrical, Pyrex jar and concentrated on the steam bath during 5 days to a sticky, tarry residue. The residue was mixed with $500 \mathrm{ml}$ of absolute ethanol, and the mixture was gently heated on the steam bath while $200 \mathrm{~g}$ of concentrated ammonium hydroxide (sp g1 0.90) was added dropwise.

The mixture was reconcentrated to a tarry residue, cooled to $40{ }^{\circ} \mathrm{C}$, and dissolved in 3 liters of chloroform, with the formation of a deepbrown solution which was filtered through filterpaper pulp, transferred to a separatory funnel, and washed with $100-\mathrm{ml}$ portions of water until the aqueous washings were colorless. The chloroform solution was then concentrated to half volume, and stirred while 4 liters of petroleum ether (bp, 38 to $67^{\circ} \mathrm{C}$ ) was added portionwise during 30 min, with the precipitation of a greenish-tan solid. The solid was collected by suction filtration and washed with petroleum ether; the filtrate was placed in an evaporating dish, concentrated to a paste, dissolved in chloroform, filtered, and treated with petroleum ether as above, affording more solid material. The precipitates were combined, air dried, and dried and powdered as usual; weight, $840 \mathrm{~g}$ (61 percent).

(21) Triphenyl phosphate. Triphenyl phosphate (technical grade, from Fisher Scientific Ce.; $978 \mathrm{~g}$ ) was dissolved in 2 liters of absolute ethanol in a 6-liter flask (equipped with a stirrer) on the steam bath. The solution was kept at 60 to $70^{\circ} \mathrm{C}$ and vigorously stirred while 2 liters of water at $60{ }^{\circ} \mathrm{C}$ was gradually added, affording two layers. Most of the upper (aqueous) layer was removed by decantation, and a further 2 liters of water at $60^{\circ} \mathrm{C}$ was added, with stirring, to the lower layer. The mixture was translerred to a separatory funnel, and the lower layer was drawn off and cooled, 
with stirring, until material crystallized. The crystals were collected on a Büchner funnel, air dried, and dissolved in 2 liters of absolute ethanol in a 5-liter flask on the steam bath. The hot, clear solution was filtered, cooled to room temperature, and refrigerated overnight, giving colorless crystals which were collected by suction filtration. Water was added to the filtrate, to incipient turbidity; on refrigeration, a second crop of crystals was obtained. The two crops were combined, recrystallized in the same way, and dried and powdered as usual; weight, $820 \mathrm{~g}$ ( 84 percent recovery); $\operatorname{mp} 49-50{ }^{\circ} \mathrm{C}$.

(22) Octaphenylcyclotetrasiloxane. This compound was purchased from the Silicone Products Department, General Electric Company, Waterford, New York; it was found to need no further purification or drying.

(23) Dibutyltin bis (2-ethylhexanoate). Commercial dibutyltin bis (2-ethylhexanoate) ${ }^{6} \quad(2,500 \mathrm{~g})$ was dissolved in 2 liters of absolute methanol in a 6-liter flask on the steam bath. The hot solution was filtered twice, transferred to a 6-liter, Pyrex jar (placed in an ice bath and equipped with a stirrer), and vigorously stirred while precipitation occurred. After the mixture had been stirred for about 2 hr at 5 to $10^{\circ} \mathrm{C}$, the crystals were collected by suction filtration. The filtrate was concentrated to half volume, filtered, and refrigerated overnight, yielding a second crop of crystals that was combined with the first crop and air dried. The compound was recrystallized once by the same procedure, and dried and powdered as usual; weight, 1,868 g (75-percent recovery).

(24) Bis(1-phenyl-1,3-butanediono) oxo-vanadium $(I V)$. This compound had previously been prepared by a different method [4]. 1-Phenyl-1,3butanedione ( $324.4 \mathrm{~g}, 2$ moles) was dissolved in 2 liters of absolute ethanol in a 4-liter beaker (equipped with a stirrer) on the steam bath. The solution was maintained at 70 to $80^{\circ} \mathrm{C}$ and vigorously stirred while a hot $\left(75^{\circ}\right)$ suspension of $219.1 \mathrm{~g}$ (1.1 moles) of vanadyl sulfate dihydrate in 1 liter of water was added rapidly, producing a clear, green solution. After the solution had been heated for $10 \mathrm{~min}$, a solution of $313 \mathrm{~g}$ (2.3 moles) of sodium acetate trihydrate in $700 \mathrm{ml}$ of water at 70 to $80^{\circ} \mathrm{C}$ was added, with stirring, during $20 \mathrm{~min}$, precipitating a small quantity of green crystals. The mixture was carefully diluted with water to incipient turbidity, refrigerated overnight, diluted with an equal volume of cold water, and refrigerated for $4 \mathrm{hr}$.

The crystals were collected on a Büchner funnel, washed successively with two 200-ml portions of cold water and two $200-\mathrm{ml}$ portions of cold absolute ethanol, and air dried on the filter. The crude, dry product, weighing $379.4 \mathrm{~g}$, was dissolved in 1.6 liters of chloroform in a 3-liter beaker on the steam bath, and the solution was diluted with 2 liters of absolute ethanol and

${ }^{6}$ This compound was obtained from Metal \& Thermit Corporation, Rahway, New Jersey, under the trade name of M. \& T. Catalyst T-8, Dibutyltin di-2-ethylhexoate. transferred to a 5-liter, round-bottomed, onenecked (standard taper, 40/50) flask. The flask was attached to a rotary still by means of a modified adapter, and evaporated at $50^{\circ}$ and 5 $\mathrm{mm}$ to half volume or until crystals began to separate. The flask was kept in an ice bath for $3 \mathrm{hr}$, with frequent shaking, and the crystals were collected by suction and washed with cold absolute ethanol; the filtrate was evaporated further in the rotary still, and cooled in an ice bath, affording a second batch of crystals which was collected, combined with the first batch, air dried, recrystallized in the same way, and dried and powdered as usual; weight, $340 \mathrm{~g}$ (87 percent), $\mathrm{mp} 214-215^{\circ} \mathrm{C}$.

(25) Calcium 2-ethylhexanoate. A solution of $176.2 \mathrm{~g}$ ( 1 mole) of calcium acetate hydrate in $600 \mathrm{ml}$ of water was slowly added, with stirring, to a solution of $344.4 \mathrm{~g}$ ( 2 moles) of 2-ethylhexanoic acid in $500 \mathrm{ml}$ of 95 percent ethanol that had been neutralized with 10 percent sodium hydroxide (using phenolphthalein as indicator). The clear solution was vigorously stirred and heated on the steam bath, giving a white precipitate which was removed at about 30 -min intervals until precipitation was complete. The precipitate was added to $1,500 \mathrm{ml}$ of hot butyl acetate $\left(95-100^{\circ} \mathrm{C}\right)$ and vigorously stirred while sufficient water was added to produce a clear solution. The solution was filtered, allowed to cool to room temperature, and refrigerated overnight, giving a white precipitate which was recovered by suction filtration, again dissolved in butyl acetate, cooled, and reprecipitated. The precipitate was filtered with suction, washed with acetone, dried, and powdered as usual ; weight $290 \mathrm{~g}$.

(26) Aluminum 2-ethylhexanoate. This compound was prepared according to the procedure given for aluminum cyclohexanebutyrate. From 3 moles of 2-ethylhexanoic acid, $406 \mathrm{~g}$ (88.8 percent) of the compound was obtained.

(27) Potassium erucate. Aqueous, 5-percent potassium hydroxide solution was added to a solution of $338.6 \mathrm{~g}$ (1 mole) of recrystallized erucic acid in $1,500 \mathrm{ml}$ of 95 -percent ethanol (faint pink to phenolphthalein). The sclution was transferred to a large evaporating dish, concentrated on the steam bath, with frequent stirring, to a thick paste, and transferred to an 8-liter beaker equipped with a stirrer. The paste was mixed with 1 liter of water and stirred while 3 liters of acetone was added during $25 \mathrm{~min}$, with the formation of a bulky, white precipitate. After the mixture had been stirred for a few minutes, the precipitate was collected on a Büchner funnel, washed with acetone, air dried, mixed with 2.5 liters of butyl acetate, and heated (with stirring) to $90-100^{\circ} \mathrm{C}$; sufficient water was added to afford a clear solution. The hot solution was filtered, allowed to cool to room temperature, and refrigerated overnight, giving a fine, granular precipitate which was filtered with suction, washed with acetone, dried, and powdered as usual; weight, $347 \mathrm{~g}$ (92 percent). 
(28) Silver 2-ethylhexanoate. This compound was prepared according to the procedure given for silver cyclohexanebutyrate. From 2 moles $(288.4 \mathrm{~g})$ of 2-ethylhexanoic acid, $360 \mathrm{~g}$ (91 percent) of the pure, dry salt was obtained.

\subsection{Other Compounds Investigated}

\subsubsection{Erucates and 2-Ethylhexanoates}

Most of the erucate salts were prepared by the addition of an aqueous solution of the metal hydroxide or acetate to an ethanol or acetone solution of the required amount of purified erucic acid [5]. Erucates not prepared by this method were obtained by addition of an aqueous solution of a salt of the desired metal to a warm methanol solution of potassium erucate. This caused the precipitation of crude product; the reaction mixture was then cooled in the refrigerator for several hours, and the product was separated by filtration and washed. The crude salt was triturated in a large beaker with large amounts of water. After thorough extraction, tlie product was filtered off, air dried, dissolved in hot butyl acetate, the suspension filtered, and the solution cooled slowly. After $18 \mathrm{hr}$, the product was separated, and washed with a suitable solvent (acetone or methanol). The material was recrystallized several times and then dried in a rotary drier under diminished pressure.

Freshly prepared stannic erucate dissolves in mineral oil, but the salt, on drying and keeping, becomes insoluble and no means has been found for preparing solutions of this dried compound in oils.

The 2-ethylhexanoates were prepared by procedures analogous to those outlined for the erucates. However, acetone and methanol were ineffective as precipitants for these salts, most of which could only be isolated as oils.

\subsubsection{Dialkyldithiocarbamates}

The sodium salts of the dialkyldithiocarbamic acids were prepared by slowly mixing a cold, 10-percent, alcoholic solution of the secondary amine with an equimolar quantity of cold carbon disulfide in ethanol and then slowly adding an equimolar quantity of 10-percent aqueous sodium hydroxide, with stirring until all turbidity disappeared.

Ordinarily, the sodium salt was used directly (without isolation) for the preparation of other salts, by mixing its aqueous solution with the calculated quantity of a 10-percent aqueous solution of the appropriate metal salt of an inorganic acid. However, it was observed that, if the sodium dialkyldithiocarbamate is isolated by removal of the solvent, the difficulty encountered in obtaining certain of the salts as solids is greatly lessened.

Most of the salts of the dialkyldithiocarbamic acids crystallize readily and are easily purified by recrystallization from ethanol, or from a mixture of ethanol and chloroform or benzene.

The preparation of lead dibutyldithiocarbamate is typical of the methods used.

Preparation of lead dibutyldithiocarbamate. A 10 -percent aqueous solution of lead nitrate (0.05 mole) was added dropwise, with mechanical stirring, to an aqueous solution of commercial sodium dibutyldithiocarbamate $(0.1$ mole $)$. Crude lead dibutyldithiocarbamate separated as a gum, from which the supernatant liquor was decanted; the product was triturated with large amounts of water, filtered, air dried, dissolved in hot isopropyl alcohol, and the suspension filtered. 'The filtrate was cooled, and the resulting crystals were filtered off, air dried, and recrystallized in the same way. Cold methanol was used for washing the crystals. Finally, the pure product was dried in a rotary drier at $60^{\circ} \mathrm{C}$ and $1 \mathrm{~mm}$; it had $\mathrm{mp} 78.5-79.0^{\circ} \mathrm{C}$.

\subsubsection{Azomethine Chelates}

The azomethines were prepared by mixing the aldehyde or ketone with an equimolar quantity of the appropriate amine, using methanol as the solvent. The metal chelate was then prepared by adding an aqueous solution of the inorganic salt to the Schiff base, followed by addition of sodium acetate. The mixture was kept at incipient boiling for about $30 \mathrm{~min}$ and left under refrigeration overnight.

The copper, nickel, and vanadium chelates of $N$-salicylidene-2-ethylhexylamine were obtained as crystalline compounds having excellent solubility in oils, but its iron, cobalt, and aluminum chelates were only obtained as oils.

Preparation of Bis (N-salicylidene-2-ethylhexylamino)oxovanadium (IV). 'To prepare this compound [6], $12.9 \mathrm{~g}$ (0.1 mole) of 2-ethylhexylamine was added to a solution of $12.2 \mathrm{~g}(0.1 \mathrm{~mole})$ of salicylaldehyde in $100 \mathrm{ml}$ of absolute ethanol. The mixture was allowed to stand for about 30 min, and $100 \mathrm{ml}$ of a 5-percent aqueous solution of vanadyl sulfate dihydrate $(0.05$ mole) was added. After thorough mixing, $50 \mathrm{ml}$ of a 10 percent aqueous sodium acetate solution was added, and the mixture was heated on the steam bath for $30 \mathrm{~min}$. A brown oil was precipitated; it was separated by decantation and washed several times with hot water. Finally, the crude product (about $25 \mathrm{~g}$ ) was dissolved in $80 \mathrm{ml}$ of ethanol and refrigerated overnight. The green crystals were separated and dried in vacuo over phospliorus pentaoxide for $12 \mathrm{hr}$. The product was recrystallized three times by the same metlod; yield, $23 \mathrm{~g}$; $\mathrm{mp} \quad 93-93.5{ }^{\circ} \mathrm{C}$. This compound dissolves readily in bis(2-ethylhexyl)dithiocarbamic acid. The solution is stable for only a few days, but the stability is improved by the addition of naphthenic acid and, possibly, by the addition of 6-methyl-2,4-lieptanedione.

Similar complexes of copper and nickel were prepared in the same manner; both of these chelates appeared to have satisfactory solubility in oils. 
TABLE 8. Spectrographic analysis of standard samples

\begin{tabular}{|c|c|c|c|c|c|}
\hline $\begin{array}{c}\text { Standard } \\
\text { Sample } \\
\text { No. }\end{array}$ & $\begin{array}{c}\text { Major } \\
\text { element }\end{array}$ & Minor elements & $\begin{array}{c}\text { Standard } \\
\text { Sample } \\
\text { No. }\end{array}$ & $\begin{array}{l}\text { Major } \\
\text { element }\end{array}$ & Minor elements \\
\hline $\begin{array}{l}1050 \\
1051 \\
1051 \mathrm{a} \\
1052 \\
1052 \mathrm{a}\end{array}$ & $\begin{array}{l}\mathrm{Al} \\
\mathrm{Ba} \\
\mathrm{Ba} \\
\mathrm{V} \\
\mathrm{V}\end{array}$ & $\begin{array}{l}\mathrm{Fe}, \mathrm{Si}(<0.01) \\
\mathrm{Sr}(<0.1) ; \mathrm{Ca}, \mathrm{Si}, \mathrm{Sn}(<0.01) \\
\mathrm{Sr}(<0.1) ; \mathrm{Ca}, \mathrm{Na}(<0.01) \\
\mathrm{Al}(<0.1) \\
<0.01 \text {, of any }\end{array}$ & $\begin{array}{l}1063 \\
1063 a \\
1064 \\
1065 \\
1065 a \\
1066\end{array}$ & $\begin{array}{l}\mathrm{B} \\
\mathrm{B} \\
\mathrm{Hg} \\
\mathrm{Ni} \\
\mathrm{Ni} \\
\mathrm{Si}\end{array}$ & $\begin{array}{l}\text { Si }(<0.01) \\
<0.01, \text { of any } \\
\mathrm{Na}, \mathrm{Mg}, \mathrm{Si}(<0.01) \\
\mathrm{Cu}, \mathrm{Fe}(<0.01) \\
<0.01 \text {, of any } \\
<0.01 \text {, of any }\end{array}$ \\
\hline $\begin{array}{l}1053 \\
1054 \\
1055 \\
1055 a \\
1056\end{array}$ & $\begin{array}{l}\mathrm{Cd} \\
\mathrm{Ca} \\
\mathrm{Co} \\
\mathrm{Co} \\
\mathrm{Cu}\end{array}$ & $\begin{array}{l}<0.01 \text {, of any } \\
\mathrm{Sr}(<0.1) ; \mathrm{K}, \mathrm{Si}(<0.01) \\
\mathrm{Ni}, \mathrm{Sn}(<0.1): \mathrm{Al}, \mathrm{Cu}, \mathrm{Fe}, \mathrm{Mn}(<0.01) \\
\mathrm{Ni}(<0.1) ; \mathrm{Cu}, \mathrm{Si}(<0.01) \\
\mathrm{Al}, \mathrm{Si}(<0.01)\end{array}$ & $\begin{array}{l}1067 \\
1068 \\
1069 \\
1069 a\end{array}$ & $\begin{array}{l}\mathrm{K} \\
\mathrm{Ag} \\
\mathrm{Na} \\
\mathrm{Na}\end{array}$ & $\begin{array}{l}\mathrm{Na}, \mathrm{Sr}(<0.1) ; \mathrm{Ca}, \mathrm{Fe}, \mathrm{Si}(<0.01) \\
\mathrm{Si}(<0.01) \\
\mathrm{Al}, \mathrm{Si}(<0.01) \\
<0.01 \text {, of any }\end{array}$ \\
\hline $\begin{array}{l}1056 a \\
1057 \\
1057 a \\
1055 \\
1059\end{array}$ & $\begin{array}{l}\mathrm{Cu} \\
\mathrm{Sn} \\
\mathrm{Sn} \\
\mathrm{Fe} \\
\mathrm{Pb}\end{array}$ & $\begin{array}{l}<0.01 \text {, of any } \\
<0.01 \text { of any } \\
<0.01 \text {, of any } \\
\text { Al, Mn, Mo, Si, Sn }(<0.01) \\
\text { Sn }(<0.1) ; \mathrm{Fe}(<0.01)\end{array}$ & $\begin{array}{l}1070 \\
1070 \mathrm{a} \\
1071 \\
1071 \mathrm{a} \\
1072\end{array}$ & $\begin{array}{l}\mathrm{Sr} \\
\mathrm{Sr} \\
\mathrm{P} \\
\mathrm{P} \\
\mathrm{Cr}\end{array}$ & $\begin{array}{l}\mathrm{Ca}(<0.1) ; \mathrm{Ba}(<0.01) \\
\mathrm{Ca}(<0.1) ; \mathrm{Ba}(<0.01) \\
<0.01, \text { of any } \\
<0.01 \text {, of any } \\
\mathrm{Ba}(<0.1) ; \mathrm{Al}, \mathrm{Si}, \mathrm{Sr}(<0.01)\end{array}$ \\
\hline $\begin{array}{l}1059 \mathrm{a} \\
1060 \\
1060 \mathrm{a} \\
1061 \\
1061 \mathrm{a} \\
1062 \\
1062 \mathrm{a}\end{array}$ & $\begin{array}{l}\mathrm{Pb} \\
\mathrm{Li} \\
\mathrm{Li} \\
\mathrm{Mg} \\
\mathrm{Mg} \\
\mathrm{Mn} \\
\mathrm{Mn}\end{array}$ & $\begin{array}{l}<0.01 \text {, of any } \\
\mathrm{Ca}, \mathrm{Na}(<0.1) ; \mathrm{Al}, \mathrm{K}, \mathrm{Si}(<0.01) \\
<0.01 \text {, of any } \\
\mathrm{Mn}(<0.01) \\
<0.01 \text {, of any } \\
\mathrm{Sr}(<0.1) ; \mathrm{Al}, \mathrm{Pb}, \mathrm{Mo}, \mathrm{Sn}(<0.01) \\
<0.01 \text {, of any }\end{array}$ & $\begin{array}{l}1073 \\
1073 \mathrm{a} \\
1074 \\
1075 \\
1076 \\
1077\end{array}$ & $\begin{array}{l}\mathrm{Zn} \\
\mathrm{Zn} \\
\mathrm{Ca} \\
\mathrm{Al} \\
\mathrm{K} \\
\mathrm{Ag}\end{array}$ & $\begin{array}{l}\mathrm{Ca}, \mathrm{Mg}, \mathrm{Ni}, \mathrm{Si}(<0.01) \\
<0.01 \text {, of any } \\
\mathrm{Ba}, \mathrm{Na}, \mathrm{Sr}(<0.01) \\
\mathrm{Si}(<0.01) \\
\mathrm{Al}, \mathrm{Ca}, \mathrm{Mg}, \mathrm{Si}(<0.01) \\
\mathrm{Si}(<0.01)\end{array}$ \\
\hline
\end{tabular}

\subsection{Spectrographic Analysis}

Spectrographic analysis was applied in rapid surveys of preliminary and final samples for qualitative or semiquantitative analysis for 50 or more chemical elements. In this procedure, a small sample was volatilized in an electric arc, the spectrum of the arc was photographed, and the spectrogram was examined for the presence of prominent spectral lines of the various elements by comparison with a standard reference spectrum. Semiquantitative estimates of ranges of concentration of the impurities were reported. For the elements found present in significant amounts, quantitative determinations were made subsequently by chemical analysis or by spectrographic analysis relative to synthesized standards.

The detailed procedures and apparatus used for the semiquantitative analyses were as follows. A 5-mg portion ol the powdered sample was mixed with $2 \mathrm{mg}$ of high-purity graphite powder, which acted as a buffer to assist in volatilizing the sample. The charge was placed in a graphite electrode (liaving a shallow cup) and was vaporized and excited in a direct-current arc, with a starting current of 5 amp and a running current of $15 \mathrm{amp}$. The light from the arc, passing through the slit of the spectrograph, was dispersed into a spectrum and this was photographed in the spectral range from 2,200-4,800 A on Eastman 33 plates. The spectrograph used for this work employed a Wadsworth mounting of a concave grating which had 15,000 lines per inch and a radius of curvature of $21 \mathrm{ft}$, and which produced a spectrum with linear, reciprocal dispersion of $5 \mathrm{~A}$ per $\mathrm{mm}$ in the first order. In some cases, where greater sensitivity was desired for the alkali metals, the spectrum was also photographed in the range 4,800-7,000 A, with an Eastman I-N plate.

The elements searched for in all samples included the following: $\mathrm{Ag}, \mathrm{Al}, \mathrm{As}, \mathrm{Au}, \mathrm{B}, \mathrm{Ba}, \mathrm{Be}, \mathrm{Bi}$,
$\mathrm{Ca}, \mathrm{Cd}, \mathrm{Ce}, \mathrm{Co}, \mathrm{Cr}, \mathrm{Cu}, \mathrm{Fe}, \mathrm{Ga}, \mathrm{Ge}, \mathrm{Hf}, \mathrm{Hr}$, In, Ir, La, Mg, Mn, Mo, Nb, Ni, Os, P, Pb, Pd, Pt, Rh, Ru, Sb, Sc, Si, Sn, Sr, Ta, Te, Th, Ti, Tl, U, $\mathrm{V}, \mathrm{W}, \mathrm{Y}, \mathrm{Zn}$, and Zr. In addition, Cs, K, Li, $N_{a}$, and $\mathrm{Rb}$ were sought in alkali samples, using the special conditions described in the preceding paragraph.

The results of spectrographic semiquantitative analyses of the final materials issued as standard samples are given in table 8 .

As a check on the semiquantitative analysis, quantitative spectroscopic analysis was made for impurities in nickel cyclohexanebutyrate (Standard Sample 1065), using a procedure similar to that of ASTM Tentative Method E129-57'T, in which the sample is ignited to form the oxide, and analysis is made by direct-current arc excitation relative to standard samples prepared in oxide form. The results of this analysis, given in percentage of the element in the original metalloorganic compound, are given below.

\begin{tabular}{l|r|l|r}
\hline & 0.004 & $\mathrm{Ti}$ & $<0.0002$ \\
$\mathrm{Fe}$ & .001 & $\mathrm{Mo}$ & $<.0002$ \\
$\mathrm{Si} \ldots .0006$ & $\mathrm{Al}$ & $\leq .0002$ \\
$\mathrm{C} 0 \ldots .0004$ & $\mathrm{Mg}$ & $<.0002$ \\
\hline
\end{tabular}

\subsection{Chemical Analysis}

For each determination, a sample (approximately $1 \mathrm{~g}$ ) was dried over phosphorus pentaoxide for the time recommended in table 5, accurately weighed, and analyzed. All analyses were performed in duplicate, at least. The analytical results are given in table 6 .

For decomposition prior to analysis, two methods were mainly employed. For 22 of the standard samples, decomposition was accomplished either by (a) wet-ashing with sulfuric

7 Methods for Emission Spectrochemical Analysis, 3d ed., pp 130-43 (American Society for Testing Materials, Philadelphia, 1960). 
and nitric acids, followed by determination of the element in the solution by appropriate methods, or (b) ignition. For 13 of the compounds, both inethods were applied. The residue obtained by ignition was either (a) weighed as the oxide; (b) treated with sulfuric acid and the sulfate weighed; (c) reduced with hydrogen and the metal weighed; or (d) dissolved in acid and the metal determined by various means. However, menthyl borate (Standard Sample 1063) was fused with sodium peroxide, and the organic material of mercuric cyclohexanebutyrate (Standard Sample 1064) was extracted with chloroform. Triphenyl phosphate (Standard Sample 1071a) was decomposed by wet-ashing with perchloric and nitric acids.

The details of the methods of analysis for each standard sample are given in the next four subsections.

\subsubsection{Wet-ashing; Ignition}

Aluminum cyclohexanebutyrate (Standard Sample 1050). Aluminum was determined by wet-ashing, precipitating with ammonium hydroxide, and igniting the filtered precipitate to aluminum oxide at $1,100{ }^{\circ} \mathrm{C}$. Determinations were also made by direct ignition of a sample, wrapped in filter paper and covered with oxalic acid, to aluminum oxide at $1,100{ }^{\circ} \mathrm{C}$.

Barium cyclohexanebutyrate (Standard Sample 1051). Barium was determined by wet-ashing, filtering the barium sulfate, and weighing it after ignition at $1,000^{\circ} \mathrm{C}$. Determinations were also made by direct ignition of a sample wrapped in filter paper and covered with oxalic acid. The residue was converted into barium sulfate and weighed after ignition at $900{ }^{\circ} \mathrm{C}$.

Bis(1-phenyl-1,3-butanediono)oxovanadium (IV) (Standard Sample 1052). Vanadium was determined by wet-ashing, oxidizing the vanadium with nitric acid, and titrating the vanadium with ferrous ammonium sulfate solution. Determinations were also made by direct ignition of a sample wrapped in filter paper and covered with oxalic acid. The oxide was ignited at $800{ }^{\circ} \mathrm{C}$ and weighed as vanadium pentaoxide.

Calcium cyclohexanebutyrate (Standard Sample 1054). Calcium was determined by wet-ashing, precipitating the calcium sulfate in alcoholic solution, and weighing the calcium sulfate after ignition at $600{ }^{\circ} \mathrm{C}$. Determinations were also made by direct ignition of a sample wrapped in filter paper and covered with oxalic acid. The oxide was converted into calcium sulfate, and weighed after ignition at $700{ }^{\circ} \mathrm{C}$.

Copper cyclohexanebutyrate (Standard Sample 1056). Copper was determined by wet-ashing, depositing the copper by electrolysis, and weighing as metallic copper. Determinations were also made by direct ignition of a sample wrapped in filter paper and covered with oxalic acid. The oxide was ignited under hydrogen, and weighed as the metal.
Ferric

1058). Iron was determined by wet-ashing, precipitating with ammonium hydroxide, dissolving the precipate in hydrochloric acid, reducing with stannous chloride, and titrating with potassium dichromate. Determinations were also made by direct ignition of a sample, wrapped in filter paper and covered with oxalic acid, to ferric oxide at $1050{ }^{\circ} \mathrm{C}$.

Lead cyclohexanebutyrate (Standard Sample 1059). Lead was determined by wet-ashing, filtering the lead sulfate through a porcelain frit, and weighing the lead sulfate after ignition at $600^{\circ} \mathrm{C}$. Determinations were also made by direct ignition of a sample wrapped in filter paper and covered with oxalic acid. The oxide was dissolved in nitric acid, precipitated with chromate, and weighed as lead chromate after drying at $140{ }^{\circ} \mathrm{C}$.

Magnesuum cyclohexanebutyrate (Standard Sample 1061). Magnesium was determined by wetashing, precipitating twice as magnesium ammonium phosphate, and weighing the magnesium pyrophosphate after ignition at $1,000{ }^{\circ} \mathrm{C}$. Determinations were also made by direct ignition of a sample wrapped in filter paper and covered with oxalic acid. The residue was converted into magnesium sulfate and weighed after ignition at $700^{\circ} \mathrm{C}$.

Manganous cyclohexanebutyrate (Standard Sample 1062). Manganese was determined by wetashing, oxidizing the manganese with ammonium persulfate, and titrating the manganese with sodium arsenite solution. Determinations were also made by direct ignition of a sample wrapped in filter paper and covered with oxalic acid. The residue was converted into manganous sulfate and weighed after ignition at $700{ }^{\circ} \mathrm{C}$.

Nickel cyclohexanebutyrate (Standard Sample 1065). Nickel was determined by wet-ashing, precipitating with dimethylglyoxime, and weighing the nickel dimethylglyoxime precipitate after drying at $150^{\circ} \mathrm{C}$. Determinations were also made by direct ignition of a sample wrapped in filter paper and covered with oxalic acid. The oxide was ignited under hydrogen and weighed as the metal.

Potassium cyclohexanebutyrate (Standard Sample 1067). Potassium was determined by wet-ashing, removing the excess acid by evaporation, and weighing the potassium as potassium sulfate after ignition at $650{ }^{\circ} \mathrm{C}$. Determinations were also made by direct ignition of a sample wrapped in filter paper and covered with oxalic acid. The residue was converted either into potassium sulfate or potassium chloride and weighed after ignition at $650^{\circ} \mathrm{C}$.

Strontium cyclohexanebutyrate (Standard Sample 10\%0). Strontium was determined by wet-ashing, precipitating the strontium sulfate in alcoholic solution, and weighing the strontium sulfate after ignition at $600{ }^{\circ} \mathrm{C}$. Determinations were also made by direct ignition of a sample wrapped in filter paper and covered with oxalic acid. 'The residue was converted into strontium sulfate, and weighed after ignition at $700{ }^{\circ} \mathrm{C}$. 
Zinc cyclohexanebutyrate (Standard Sample 1073). Zinc was determined by wet-ashing, precipitating with hydrogen sulfide from $0.01 N$ acid, and igniting the filtered precipitate to zinc oxide at $950^{\circ} \mathrm{C}$. Determinations were also made by direct ignition of a sample, wrapped in filter paper and covered with oxalic acid, to zinc oxide at $950^{\circ} \mathrm{C}$.

\subsubsection{Wet-ashing}

Cadmium cyclohexanebutyrate (Standard Sample 1053). Cadmium was determined by wet-ashing, electrodepositing the cadmium from an alkaline cyanide solution, or from 0.5-percent sulfuric acid solution, and weighing the metal.

Dibutyltin bis(2-ethylhexanoate) (Standard Sample 105\%). Tin was determined by wet-ashing, precipitating the tin with cupferron, and igniting to stannic oxide at $1,000{ }^{\circ} \mathrm{C}$. Determinations were also made by wet-ashing, reducing the tin with metallic nickel, and titrating the tin with potassium iodate solution.

Lithium cyclohexanebutyrate (Standard Sample 1060). Lithium was determined by wet-ashing, removing the excess acid by evaporation, and weighing the lithium as lithium sulfate after ignition at $600{ }^{\circ} \mathrm{C}$.

Octaphenylcyclotetrasiloxane (Standard Sample 1066). Silicon was determined by wet-ashing, dehydrating the silica twice, igniting the silica at $1,100{ }^{\circ} \mathrm{C}$, and volatilizing the silicon with hydrofluoric acid.

Triphenyl phosphate (Standard Sample 1071). Phosphorus was determined by wet-ashing, twice precipitating with magnesia mixture, and igniting to magnesium pyrophosphate at $1,000{ }^{\circ} \mathrm{C}$. Phosphorus was also determined (for Standard Sample 1071a) by wet-ashing with perchloric and nitric acids, precipitating the phosphorus with quinoline in the presence of sodium inolybdate, drying the precipitate at $250^{\circ} \mathrm{C}$, and weighing as

$$
\left(\mathrm{C}_{9} \mathrm{H}_{7} \mathrm{~N}\right)_{3} \cdot \mathrm{H}_{3} \mathrm{PO}_{4} \cdot 12 \mathrm{MoO}_{3} \text {. }
$$

Tris $\left(2^{\prime}-h y d r o x y a c e t o p h e\right.$ no no) chromium (III) (Standard Sample 1072). Chromium was determined by wet-ashing, oxidizing the chromium with ammonium persulfate, and titrating the chromium with ferrous ammonium sulfate solution.

\subsubsection{Ignition}

Cobalt cyclohexanebutyrate (Standard Sample 1055). Cobalt and nickel (minor constituent) were determined by ignition of a sample wrapped in filter paper and covered with oxalic acid. The mixture of oxides was dissolved in hydrochloric acid, electrodeposited as cobalt plus nickel from ammoniacal solution, and weighed as the metals. The oxide mixture was also ignited under hydrogen and weighed as the metals. Nickel was separated from a hydrochloric acid solution of the metals by anion exchange, precipitated with dimethylglyoxime, and weighed.

Silver cyclohexanebutyrate (Standard Sample 1068). Silver was determined by direct ignition of a sample wrapped in filter paper and covered with oxalic acid. The oxide was ignited under hydrogen and weighed as the metal. Determinations were also made by dissolving the ignited oxide in nitric acid, precipitating with hydrochloric acid, and weighing the silver chloride.

Sodium cyclohexanebutyrate (Standard Sample 1069). Sodium was determined by direct ignition of a sample wrapped in filter paper and covered with oxalic acid. The residue was either converted into sodium sulfate and weighed after ignition at $900{ }^{\circ} \mathrm{C}$ or converted into sodium chloride and weighed after ignition at $600^{\circ} \mathrm{C}$.

Calcium 2-ethylhexanoate (Standard Sample 10\%.). Calcium was determined by direct ignition of a sample wrapped in filter paper and covered with oxalic acid. The residue was dissolved in hydrochloric acid, the calcium precipitated as calcium oxalate, and the calcium oxalate titrated with potassium permanganate solution.

\subsubsection{Other Procedures}

Menthyl borate (Standard Sample 1063). Boron was determined by bomb-fusing an $0.5-\mathrm{g}$ sample with sodium peroxide and titrating the resulting boric acid with standard sodium hydroxide after the addition of mannitol.

Mercuric cyclohexanebutyrate (Standard Sample 1064). Mercury was determined in a sample by titration with ammonium thiocyanate, after extraction of organic matter with chloroform. Determinations wele also made by extracting a sample with chloroform, precipitating the mercury with hydrogen sulfide, drying the precipitate at $110^{\circ} \mathrm{C}$, and weighing as mercuric sulfide.

\subsection{Weight-stability of Standard Compounds}

Preliminary studies showed that some of the compounds chosen as standards are fairly hygroscopic. Furthermore, drying by gentle heating (e.g., to $60^{\circ} \mathrm{C}$ ) at atmospheric pressure or in a vacuum oven was, in some instances, deleterious. Consequently, in order to ascertain the time for maximum absorption of moisture by each compound and the rate of drying after maximum absorption, the following procedure was employed.

A specimen (approximately $1 \mathrm{~g}$ ) of the standard sample was transferred from the bottle to a weighing bottle (ground-glass stopper) and accurately weighed. The stopper was then removed and the material was exposed to an atmosphere of approximately 75 percent humidity in a closed desiccator containing a dish of saturated, aqueous sodium chloride solution. After the elapse of various periods of time, the stopper was replaced in the weighing bottle and the weight was determined. When equilibrium had been reached, the sample was dried in a desiccator containing phosphorus pentaoxide until the weight was constant. Most of the determinations were made in duplicate.

In addition, a 1-g specimen of each standard sample, as received by the analyst, was dried to constant weight over phosphorus pentaoxide in a desiccator. The percent loss in weight is given in column 4 of table 9 . 
TABLE 9. Loss in weight on drying, gain in weight at 75 percent humidity, and loss in weight on drying humidifled material, for the standard samples

\begin{tabular}{|c|c|c|c|c|c|c|c|c|c|}
\hline \multirow{4}{*}{$\begin{array}{c}\text { Serial } \\
\text { No. }\end{array}$} & \multirow{4}{*}{$\begin{array}{c}\text { NBS } \\
\text { Standard } \\
\text { Sample } \\
\text { No. }\end{array}$} & \multicolumn{5}{|c|}{ Original material a } & \multirow{2}{*}{\multicolumn{3}{|c|}{ Dumidified material ${ }^{b}$}} \\
\hline & & \multicolumn{2}{|c|}{ Dried over $\mathrm{P}_{2} \mathrm{O}_{5}$} & \multicolumn{3}{|c|}{ In $75 \%$ humidity } & & & \\
\hline & & \multirow{2}{*}{$\begin{array}{l}\text { Timo } \\
\text { to } \\
\text { equil }\end{array}$} & \multirow{2}{*}{$\begin{array}{l}\text { Loss in } \\
\text { wt at } \\
\text { equil }\end{array}$} & \multirow{2}{*}{$\begin{array}{l}\text { Time } \\
\text { to } \\
\text { equil }\end{array}$} & \multicolumn{2}{|c|}{ Gain in wt c } & \multirow{2}{*}{$\begin{array}{c}\text { Timed } \\
\text { to } \\
\text { equil }\end{array}$} & \multicolumn{2}{|c|}{ Loss in weight $c$} \\
\hline & & & & & $\operatorname{in}_{7 \mathrm{hr}}$ & $\begin{array}{c}\text { at } \\
\text { cquil }\end{array}$ & & $\operatorname{in}_{7 \mathrm{hr}}$ & at \\
\hline $\begin{array}{l}1 \\
2 \\
3 \\
4\end{array}$ & $\begin{array}{l}1050 \\
1051 \\
1051 \mathrm{a} \\
1053 \\
1054\end{array}$ & $h r \begin{array}{r} \\
24 \\
24 \\
24 \\
48 \\
48\end{array}$ & $\begin{array}{l}\% \\
1.0 \\
1.3 \\
0.9 \\
5.7 \\
0.1\end{array}$ & $\begin{array}{ll}h r & \\
2 \\
2 \\
2 \\
7 \\
7 \\
7\end{array}$ & $\begin{array}{l}\% \\
0.08 \\
1.1 \\
1.9 \\
1.6 \\
0.06\end{array}$ & $\begin{array}{l}\% \\
0.08 \\
1.1 \\
1.9 \\
1.6 \\
0.06\end{array}$ & $\begin{array}{r}h r \\
2 \\
24 \\
24 \\
48 \\
48\end{array}$ & $\begin{array}{l}\% \\
1.0 \\
2.1 \\
2.2 \\
1.6 \\
0.09\end{array}$ & $\begin{array}{l}\text { \% } \\
1.0 \\
2.5 \\
2.8 \\
7.2 \\
0.2\end{array}$ \\
\hline $\begin{array}{l}5 .- \\
6 .- \\
7 .-\end{array}$ & $\begin{array}{l}1055 \\
1055 \mathrm{a} \\
1056 \\
1056 \mathrm{a} \\
1058\end{array}$ & $\begin{array}{r}24 \\
48 \\
2 \\
2 \\
24\end{array}$ & $\begin{array}{l}1.0 \\
1.2 \\
0.01 \\
.02 \\
.6\end{array}$ & $\begin{array}{r}24 \\
48 \\
2 \\
2 \\
2\end{array}$ & $\begin{array}{l}.06 \\
.8 \\
.01 \\
.03 \\
.2\end{array}$ & $\begin{array}{l}.1 \\
1.1 \\
0.01 \\
.02 \\
.2\end{array}$ & $\begin{array}{r}24 \\
48 \\
2 \\
2 \\
24\end{array}$ & $\begin{array}{l}0.08 \\
1.5 \\
0.02 \\
.06 \\
.7\end{array}$ & $\begin{array}{l}1.1 \\
2.5 \\
0.02 \\
.05 \\
.8\end{array}$ \\
\hline $\begin{array}{l}8 \ldots \\
9 \ldots \\
10\end{array}$ & $\begin{array}{l}1059 \\
1059 \mathrm{a} \\
1060 \\
1060 \mathrm{a} \\
1061 \\
1061 \mathrm{a}\end{array}$ & $\begin{array}{r}24 \\
2 \\
24 \\
7 \\
216 \\
48\end{array}$ & $\begin{array}{l}.4 \\
.02 \\
.5 \\
.4 \\
2.6 \\
0.3\end{array}$ & $\begin{array}{r}2 \\
16 \\
168 \\
168 \\
336 \\
336\end{array}$ & $\begin{array}{r}.2 \\
.4 \\
.3 \\
.3 \\
.3 .5 \\
4.6\end{array}$ & $\begin{array}{rr} & .2 \\
& .6 \\
2.8 \\
2.8 \\
2.3 \\
8 \\
82.2 \\
8 \\
2.2\end{array}$ & $\begin{array}{r}48 \\
2 \\
24 \\
24 \\
48 \\
48\end{array}$ & $\begin{array}{l}.9 \\
.03 \\
2.5 \\
1.8 \\
2.0 \\
1.4\end{array}$ & $\begin{array}{l}1.2 \\
0.01 \\
3.5 \\
3.0 \\
2.8 \\
1.6\end{array}$ \\
\hline $\begin{array}{l}11 \\
12 \\
13\end{array}$ & $\begin{array}{l}1062 \\
1062 \mathrm{a} \\
1064 \\
1065 \\
1065 \mathrm{a}\end{array}$ & $\begin{array}{r}144 \\
24 \\
2 \\
72 \\
24\end{array}$ & $\begin{array}{l}1.9 \\
0.5 \\
.01 \\
.7 \\
.5\end{array}$ & $\begin{array}{r}24 \\
72 \\
2 \\
168 \\
48\end{array}$ & $\begin{array}{l}0.8 \\
2.5 \\
0.04 \\
.4 \\
1.5\end{array}$ & $\begin{array}{l}1.2 \\
2.7 \\
0.04 \\
.9 \\
1.9\end{array}$ & $\begin{array}{r}48 \\
72 \\
2 \\
48 \\
48\end{array}$ & $\begin{array}{l}0.8 \\
1.1 \\
0.03 \\
1.0 \\
1.2\end{array}$ & $\begin{array}{l}2.9 \\
3.3 \\
0.03 \\
1.7 \\
2.2\end{array}$ \\
\hline $\begin{array}{l}14 \\
15 \\
16 \\
17\end{array}$ & $\begin{array}{l}1067 \\
1068 \\
1069 \\
1069 \mathrm{a} \\
1070 \\
1070 \mathrm{a}\end{array}$ & $\begin{array}{r}24 \\
48 \\
2 \\
2 \\
48 \\
24\end{array}$ & $\begin{array}{l}4.9 \\
0.5 \\
.01 \\
.01 \\
.8 \\
.5\end{array}$ & $\begin{array}{r}\text { h } 48 \\
24 \\
168 \\
168 \\
2 \\
2\end{array}$ & $\begin{array}{l}0.4 \\
2.3 \\
2.2 \\
0.2 \\
.9\end{array}$ & $\begin{array}{r}30.0 \\
0.6 \\
28.0 \\
28.0 \\
0.2 \\
.9\end{array}$ & $\begin{array}{r}430 \\
24 \\
48 \\
48 \\
24 \\
24\end{array}$ & $\begin{array}{r}10.4 \\
1.7 \\
8.1 \\
8.4 \\
0.9 \\
1.0\end{array}$ & $\begin{array}{r}\text { h } 23.5 \\
2.0 \\
28.0 \\
28.0 \\
0.9 \\
1.2\end{array}$ \\
\hline $\begin{array}{c}18 \ldots \\
19 \\
20\end{array}$ & $\begin{array}{l}1073 \\
1073 a \\
1063 \\
1063 \mathrm{a} \\
1072\end{array}$ & $\begin{array}{r}2 \\
2 \\
2 \\
48\end{array}$ & $\begin{array}{l}.05 \\
.01 \\
.01 \\
.4\end{array}$ & $\begin{array}{r}48 \\
24 \\
48 \\
24 \\
2\end{array}$ & $\begin{array}{l}1.4 \\
5.0 \\
0.04 \\
.04 \\
.4\end{array}$ & $\begin{array}{r}1.8 \\
6.9 \\
0.2 \\
.1 \\
.4\end{array}$ & $\begin{array}{r}24 \\
48 \\
2 \\
2 \\
48\end{array}$ & $\begin{array}{l}1.7 \\
1.7 \\
0.01 \\
.06 \\
.8\end{array}$ & $\begin{array}{l}3.6 \\
7.2 \\
0.01 \\
.04 \\
1.0\end{array}$ \\
\hline $\begin{array}{l}21_{--} \\
22_{--} \\
23_{--}\end{array}$ & $\begin{array}{l}1071 \\
1071 \mathrm{a} \\
1066 \\
1057 \\
1057 \mathrm{a}\end{array}$ & $\begin{array}{l}2 \\
2 \\
2 \\
2 \\
2\end{array}$ & $\begin{array}{l}.01 \\
.01 \\
.0 \\
.01 \\
.01\end{array}$ & $\begin{array}{l}2 \\
2 \\
2 \\
2 \\
2\end{array}$ & $\begin{array}{l}.01 \\
.02 \\
.0 \\
.01 \\
.04\end{array}$ & $\begin{array}{l}.01 \\
.01 \\
.0 \\
.01 \\
.04\end{array}$ & $\begin{array}{l}2 \\
2 \\
0 \\
2 \\
2\end{array}$ & $\begin{array}{l}.01 \\
.01 \\
.0 \\
.01 \\
.02\end{array}$ & $\begin{array}{l}0.01 \\
.01 \\
.0 \\
.01 \\
.01\end{array}$ \\
\hline $\begin{array}{l}24 \\
25 \\
26 \\
27 \\
28\end{array}$ & $\begin{array}{l}1052 \mathrm{a} \\
1074 \\
1075 \\
1076 \\
1077\end{array}$ & $\begin{array}{r}2 \\
48 \\
48 \\
2 \\
2\end{array}$ & $\begin{array}{l}.02 \\
.4 \\
.5 \\
.01 \\
.01\end{array}$ & $\begin{array}{r}2 \\
48 \\
24 \\
24 \\
24\end{array}$ & $\begin{array}{l}.01 \\
5.1 \\
0.1 \\
.1 \\
.4\end{array}$ & $\begin{array}{l}.02 \\
5.6 \\
0.1 \\
.2 \\
.5\end{array}$ & $\begin{array}{r}2 \\
48 \\
48 \\
2 \\
2\end{array}$ & $\begin{array}{l}.02 \\
2.9 \\
0.5 \\
.2 \\
.5\end{array}$ & $\begin{array}{l}.02 \\
4.5 \\
0.7 \\
.2 \\
.5\end{array}$ \\
\hline
\end{tabular}

a As received by analyst.

- Kept in $75 \%$ humidity to equilibrium.

c Calculated on the weight of original material taken.

d Recommended drying time.

- The figurc in this column should be approximately cqual to the sum of the figures in columns 4 and 7 , unless hydrolysis occurred during the humidification.

The percent gain in weight, at equilibrium in 75-percent humidity, of a 1-g specimen of each standard sample (as received by the analyst) is given in column 7 of table 9 . The percent loss in weight of this humidified material, on drying to constant weight over phosphorus pentaoxide in a desiccator, is given in column 10 of table 9 . The figure in column 10 should be approximately equal to the sum of the figures in columns 4 and 7 , unless hydrolysis occurred during the humidification. Standard Samples 1059a, 1061 and 1061a, 1067, and 1074 exhibit this behavior.

From table 9, it may be seen that the weightstabilities vary widely. It was concluded that, as a precautionary measure, bottles containing standard samples should be stored, tightly closed, $f$ Gain of $3.5 \%$ after $48 \mathrm{hr}$.

$s$ This compound initially gained weight and then lost some of this gain in veight, at $75 \%$ humidity.

$h$ Equilibrium not reaehed. This compound should not be exposed to moisture.

in desiccators containing phosphorus pentaoxide, and that, before use, the required amount of a compound should be dricd over phosphorus pentaoxide for the length of time recommended in column 8 of table 9 .

\subsection{Dissolution in Petroleum Oils}

In estimating the oil-solubility of the metalloorganic and other compounds, benzene, toluene, xylene, mineral spirits, mineral oil, white paraffin oil, and base oils (which were supplied by several oil companies) were used. One or more of the following attempts at dissolving the compounds were made.

(1) Dissolving directly in oil, without heat or other solvents. 
(2) Dissolving in oil, with moderate heating (below $100^{\circ} \mathrm{C}$ ).

(3) Dissolving in benzene, toluene, xylene, or mineral spirits, and diluting with the base oil.

(4) Dissolving in a solubilizing agent (such as a free carboxylic acid, a diketone, or an ester) and diluting with the base oil.

Early in the project, it was found that very few of the compounds could be dissolved by method 1 . A slightly larger number of compounds could be dissolved by method 2, but the solutions usually redeposited material at room temperature. Method 3 gave solutions that wcre more stable. Method 4 gave the most stable and the most concentrated solutions of a given element.

These solubility tests were used both for evaluating the solubility of each compound and for comparing the solubilities of a variety of compounds of one element. The solubility of a compound was considered to be "satisfactory" if, by method 4 , a solution could be prepared that had a concentration (of the element in question) of $500 \mathrm{ppm}$. In the subsequent discussion, the term "calculated weight" of a compound refers to the weight of it which will provide $50 \mathrm{mg}$ of the element of interest per $100 \mathrm{~g}$ of the final solution. "The solution was regarded as "stable" if it remained clcar and devoid of visible change during several weeks at room temperature.

In the course of the work, a solution was developed which acts as both a solubilizer and a stabilizer of compounds dissolved in oil. This "solubilizing solution A" consists of a mixture of equimolar proportions of bis(2-ethylhexyl)amine and bis(2-ethylhexyl)dithiocarbamic acid in an equal volume of xylene.

\subsubsection{Metal 2-Ethylhexanoates}

Crude salts of 2-ethylhexanoic acid dissolved readily in benzene or xylene, and these solutions could be diluted with base oils to give stable solutions.

The purified, solid 2-ethylhexanoates of barium, calcium, copper, lead, lithium, and sodium gave stable solutions (metal concentration, $500 \mathrm{ppm}$ ) by dissolving the calculated weight in 3 to $6 \mathrm{ml}$ of 2-ethylhexanoic acid and diluting to $100 \mathrm{~g}$ with lubricating oil.

Silver 2-ethylhexanoate gave a solution (silver concentration, $500 \mathrm{ppm}$ ) by first dissolving in 2-ethylhexylamine and then diluting to $100 \mathrm{~g}$ with base oil.

The iron (III) salt was dissolved by use of 6-methyl-2,4-heptanedione and 2-ethylhexanoic acid before addition of the oil.

The chromium salt underwent changes similar to those shown by chromium erucate and, after storage, could not be dissolved.

The solid salts of nickel and cobalt were practically insoluble in all solvents tested (with base oil).

\subsubsection{Metal Erucates}

Erucates of the metals of interest were found to be insoluble in the common organic solvents. Solutions having (a) the desired concentration of metal and (b) satisfactory stability were prepared by dissolving the calculated weight of the given salt in 3 to $6 \mathrm{ml}$ of hot naphthenic acid (or hot 2-ethylhexanoic acid) and diluting to $100 \mathrm{~g}$ with lubricating oil.

Because of the high molecular weights of the metal erucates, a relatively large sample of each salt was needed in order to provide a final concentration (of metal) of $500 \mathrm{ppm}$; consequently, concentrations of $200 \mathrm{ppm}$ were tested instead.

Stable solutions of the erucates of barium, lead, lithium, magnesium, potassium, sodium, strontium, and zinc, respectively, at a concentration of $200 \mathrm{ppm}$ of the metal, were obtained by use of 4 to $6 \mathrm{ml}$ of 2-cthylhexanoic acid as the solubilizing agent.

Silver erucate was dissolved in lubricating oil by use of solubilizing solution $\mathbf{A}$.

By use of naphthenic acid or 2-ethylhexanoic acid, freshly prepared chromium erucate dissolved in base oils, but after the dry salt had been kept at room temperature for several days, it could no longer be dissolved.

\subsubsection{Metal Dialkyldithiocarbamates}

The calculated weight of each compound dissolved readily in 3 to $5 \mathrm{ml}$ of benzene, toluene, xylene, or mineral spirits at room temperature or, in a few instances, on heating; the solution was then diluted to $100 \mathrm{ml}$ with lubricating oil, and the flask was stoppered. The solution was kept at room temperature for many weeks and was periodically observed for deposition of a precipitate or formation of a gel.

The following observations were made on dibutyldithiocarbamates: the cadmium and cobalt compounds formed gels in base oils; the iron (III) compound had low solubility; but the copper, lead, nickel, and zinc compounds were satisfactory.

As could be anticipated, highly purified samples of the metal dithiocarbamates were less soluble in oil, and showed a greater tendency to crystallize from solution, than less pure samples. However. by dissolving the calculated weight of the dithiocarbamate (of copper, lead, nickel, and zinc) in 4 to $6 \mathrm{ml}$ of solubilizing solution $A$ and then adding sufficient lubricating oil to bring the weight to $100 \mathrm{~g}$, each compound remained dissolved and the stability of the solution, on keeping, was satisfactory in all cases but one. (After a solution of lead dibutyldithiocarbamate had been kept at room temperature for several weeks, a precipitate was formed which could not be redissolved in organic solvents.) Nickel bis(2-ethylhexyl)dithiocarbamate gave solutions that were stable for many months. 


\subsubsection{Metal Chelates of Azomethines}

The copper, nickel, and vanadium chelates of $N$-salicylidene(2-ethylhexyl)amine were soluble in lubricating oil. However, the oil solution of the vanadium chelate was not sufficiently stable, unless used on the same d2y that the solution was prepared; but addition of 4 to $6 \mathrm{ml}$ of solubilizer A (per $100 \mathrm{~g}$ of final oil-solution) gave the desired stability.

\subsubsection{Metal Chelates of Diketones and Hydroxy Ketones}

The metal chelates of the diketones having low molecular weight are solublc in benzene or xylene, and less soluble in mineral spirits, but their solubility in lubricating oils is very low

The 2,4-pentanedione chelates of chromium, cobalt, copper, and iron are practically insoluble in oil, and solutions of the compounds in oil gave crystalline precipitates on being kept overnight at room temperature.

The 6-methyl-2,4-heptanedione chelates of aluminum and chromium were only obtained as oils, whicl were, however, very soluble in lubricating oil without addition of any solubilizer The chromium, cobalt, iron, lead, and vanadium chelates of 1-phenyl-1,3-butanedione and 1,3diphenyl-1,3-propanedione were also tested for oilsolubility. The chromium and iron chelates of 1-phenyl-1,3-butanedione were too low in solubility (by method 4), but the cobalt, lead, and vanadium chelates had satisfactory oil-solubility by method 4 . The stability of this solution of this vanadium chelate in oil was satisfactory.

For the vanadium chelate of 1-phenyl-1,3butanedione, a stable solution (metal concentration, $500 \mathrm{ppm}$ ) was prepared by dissolving the calculated weight in a hot solution of $3 \mathrm{ml}$ of bis(2-ethylhexyl)amine and $3 \mathrm{ml}$ of 6-methyl-2,4heptanedione in $3 \mathrm{ml}$ of xylene, adding $1 \mathrm{ml}$ of 2-cthylhexanoic acid and 80 to $90 \mathrm{ml}$ of lubricating oil, cooling to room temperature, and diluting to $100 \mathrm{~g}$ with lubricating oil. Although this vanadium compound is less oil-soluble than $\operatorname{bis}(N-$ salicylidene-2-ethylhexylamino)oxovanadium (IV), it is superior to the latter as regards (a) stability to light and air and (b) the stability of its solutions.

An oil solution of the chromium chelate of $2^{\prime}-$ hydroxyacetophenone, at a metal concentration of $500 \mathrm{ppm}$, was prepared by heating the calculated weight with a mixture of $3 \mathrm{ml}$ of 2-ethylhexanoic acid and $3 \mathrm{ml}$ of 6-methyl-2,4-heptanedionc until a clear solution formed and then diluting to $100 \mathrm{~g}$ with lubricating oil.

\subsubsection{Metal Gyclohexanebutyrates}

The solid cyclohexanebutyrates of 19 inetals were tested for solubility. The salts of cadmium, cobalt, copper, iron, lead, manganese, mercury, nickel, and zinc dissolve readily in chloroform but are less soluble in benzene or xylene.
With the exception of the chromium salt, all of the cyclohexanebutyrates studied were, by use of a solubilizer, dissolved in lubricating oil to afford stable solutions. For the salts of barium, calcium, lead, lithium, magnesium, manganese, mercury, nickel, potassium, sodium, and zinc, the calculated weight was dissolved in 4 to $6 \mathrm{ml}$ of 2 -ethylhexanoic acid, and the solution was diluted to $100 \mathrm{~g}$ with lubricating oil to afford a stable solution.

For the salts of cadmium, cobalt, copper, and silver, the calculated weight was dissolved in 4 to $6 \mathrm{ml}$ of 2-ethylhexylamine, and the solution was diluted with oil.

For the salts of aluminum and iron, the calculated weight was dissolved in a hot mixture of 2 ethylhexanoic acid and 6-methyl-2,4-heptanedione, and the solution was diluted with oil.

Chromium cyclohexanebutyrate was unsatisfactory both as regards its physical state and its low solubility in oil (with all solubilizers tested).

\subsubsection{Miscellaneous Compounds}

For the elements boron, phosphorus, and tin, the compounds that (of those tested) had the highest solubility in oil were menthyl borate, triphenyl phosphate, and dibutyltin bis(2-ethylhexanoate), respectively. Each dissolved in hot lubricating oil, at a concentration (of the element of interest) of $500 \mathrm{ppm}$, to give a stable solution. However, in routine work, it was found more practical to dissolve the calculated weight of each compound in $5 \mathrm{ml}$ of hot xylene and dilute to $100 \mathrm{~g}$ with lubricating oil.

For silicon, the only solid derivative studied was octaphenylcyclotetrasiloxane, and this is practically insoluble in oils at room temperature. Howcver, certain of the petroleum laboratories cooperating in testing the oil-solubility of the compounds discovered that this silicon compound gives a solution (silicon concentration, $200 \mathrm{ppm}$ ) which can be used satisfactorily if prepared as described in section 3.9.8.

Preparation of a stable, oil solution of the selected chromium compound has already been described (see section 3.9.5).

\subsubsection{Preparation of an Oil Solution Containing One} Element of Interest, at the Desired Concentration

The required weight of the standard sample and the volume of each solvent needed, cxcept that of the lubricating oil, are given in table 10 . The procedure is exemplified by that for aluminum cyclohexanebutyrate (Standard Sample 1050).

Transfer approximately $1.0 \mathrm{~g}$ of this compound from the bottle to a small beaker and dry over fresh phosphorus pentaoxide in a desiccator for two hours. (Tightly close the bottle containing the remainder of the compound.) Quickly and accurately transfer $0.725 \mathrm{~g}$ of this dried salt to a weighed $200-\mathrm{ml}$ flask. (This weight of salt is equivalent to $50 \mathrm{mg}$ of aluminum.) Add $3 \mathrm{ml}$ of xylene and $4 \mathrm{ml}$ of 2-ethylhexanoic acid and heat the flask on a hot plate, with swirling and without charring, until a clear gel forms. Add $3 \mathrm{ml}$ of 6-methyl-2,4-heptanedione and 


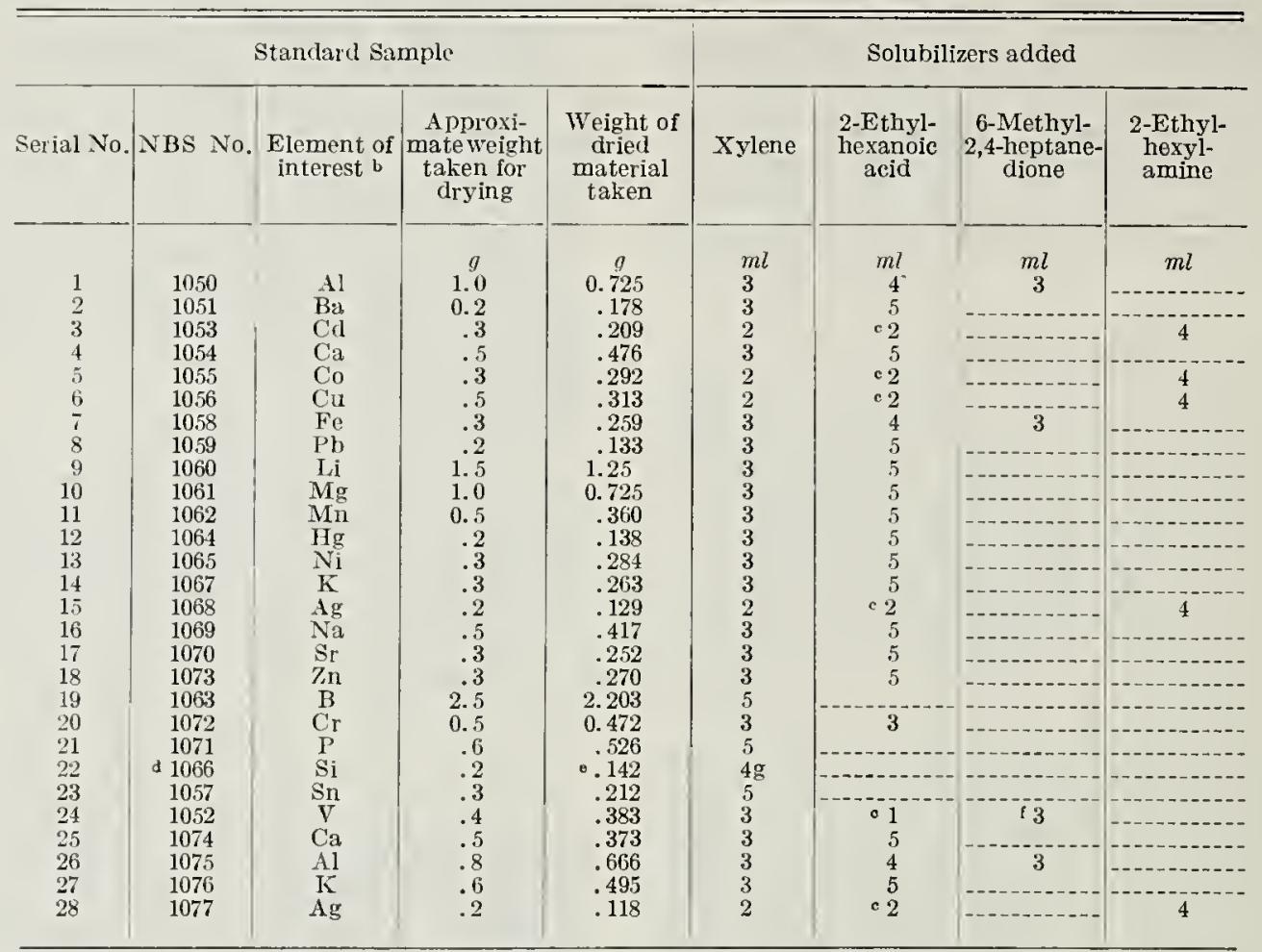

- Except for compound 22 (Standard Sample 1066)

b Wt of element, $50 \mathrm{mg}$, except for compound $22(20 \mathrm{mg})$.

- Added just before addition of the lubricating oil. d See separate description of procedure

Contains $20 \mathrm{mg}$ of Si and gives a final concentration of $200 \mathrm{ppm}$.

f Plus $3 \mathrm{ml}$ of bis-(2-ethylhexyl)amine. continue heating and swirling until the gel disappears and a clear solution forms. To the hot solution, add 80 to $90 \mathrm{ml}$ of lubricating oil, and gently shake the flask to mix the contents. Allow the flask to cool to room temperature and add enough lubricating oil to bring the total weight of the contents of the flask to $100 \pm 0.5 \mathrm{~g}$. Stopper the flask and shake gently to insure a homogeneous solution. The concentration of aluminum in this solution is 500 ppm.

Because of its low solubility, a special procedure is necessary in order to prepare an oil solution of octaphenylcyclotetrasiloxane (Standard Sample 1066).

Accurately transfer $0.142 \mathrm{~g}$ of this compound to a weighed 200-ml flask. (This weight of compound is equivalent to $20 \mathrm{mg}$ of silicon.) Add $4 \mathrm{~g}$ of xylene and heat the flask on a hot plate, with swirling and without charring, until the solid dissolves. In a separate flask, heat $95 \mathrm{~g}$ of lubricating oil to $75^{\circ} \mathrm{C}$, and carefully pour this hot oil into the silicon-containing solution. Allow the solution to cool to room temperature and add enough cool lubricating oil to bring the total weight of the contents of the flask to $100 \pm 0.5 \mathrm{~g}$. Reheat the flask immediately to $75{ }^{\circ} \mathrm{C}$ under a reflux condenser and keep the solution under the condenser, at this temperature, during use. The concentration of silicon in this solution is $200 \mathrm{ppm}$.

\subsubsection{Preparation of an Oil Solution Containing Several}

Elements of Interest, at the Desired Concentration

Stable solutions of a mixture of the compounds, containing each element of interest at the desired concentration, can be prepared.

Of the 24 compounds selected as standards, the aluminum, chromium, iron, and vanadium compounds require (a) the most heating and (b) the presence of at least two solubilizers (in xylene) for dissolution in the oil. Consequently, one (or more) of these compounds was dissolved first. Mol'eover, the compounds of silver and mercury are sensitive to prolonged heating and, so, they should be added last. For the other compounds, the order of addition is immaterial.

An appropriate solubilizer, or mixture thereof, is chosen, and the calculated weight of one of the compounds is added; this compound is dissolved completely. The other compounds are now added, one at a time, each being dissolved completely before the next one is added. As a rule, the more compounds added, the greater the solubility in the mixture. Finally, the cooled solution is diluted to $100 \mathrm{~g}$ with lubricating oil.

The volume of solubilizer needed depends on the particular mixture of compounds to be dissolved, but in no instance exceeded $12 \mathrm{ml}$ per $100 \mathrm{~g}$ of final oil-solution.

The following is a precise description of the preparation of a blend containing nine elements of interest, each at a concentration of $250 \mathrm{ppm}$.

The solubilizing agent was prepared by placing $5 \mathrm{ml}$ of 2-ethylhexanoic acid, $4 \mathrm{ml}$ of 6-methyl2,4-heptanedione, and $2 \mathrm{ml}$ of xylene in a weighed, 200-ml Erlenmeyer flask. The calculated weight of aluminum cyclohexanebutyrate (see table 11) was weighed into a small beaker and carefully transferred to the flask (without permitting the salt to touch the inside of the flask and without creation of dust of the compound). The suspension was gently heated on a hot plate, with swirling, until the salt had dissolved to a clear solution. Using a clean spatula each time, and 
TABLE 11. Order of addition and weights of compounds used for preparation of a blended solution of nine elements in oil

\begin{tabular}{|c|c|c|}
\hline Element & Compound & $\begin{array}{l}\text { Wt of } \\
\text { compound a } \\
\text { used b }\end{array}$ \\
\hline $\begin{array}{l}\mathrm{Al} \\
\mathrm{Cr} \\
\mathrm{V} \\
\mathrm{Ba} \\
\mathrm{Fe} \\
\mathrm{Cu} \\
\mathrm{Co} \\
\mathrm{Mg} \\
\mathrm{Ni}\end{array}$ & $\begin{array}{l}\text { Aluminum cyclohexanebutyrate } \\
\text { Tris (2'-hydroxyacctophenono) chromium (1II) } \\
\text { Bis (1-phenyl-1,3-butanediono) oxovanadium (IV)-- } \\
\text { Barium cy clohexancbutyrate } \\
\text { Iron cy clohexanebutyrate } \\
\text { Cupric cyclohexanebutyrate. } \\
\text { Cobalt cyclohexanebutyrate. } \\
\text { Magnesium cyclohexanebutyrate } \\
\text { Nickel cyclohcxanebutyrate. }\end{array}$ & $\begin{array}{r}g \\
0.363 \\
.236 \\
.193 \\
.089 \\
.130 \\
.157 \\
.146 \\
.363 \\
.142\end{array}$ \\
\hline
\end{tabular}

- Equivalent to $25 \mathrm{mg}$ of the particular elcment.

b Per $100 \mathrm{~g}$ of final solution, to girc a concentration (of the element) of 250 ppm.

with precautions to avoid contamination from transfer of traces of one compound to a container of another compound, the calculated weight of each of the other compounds was added, one at a time (in the order given in table 11), and completely dissolved before the next compound was added. After each addition, the mixture was gently heated, tilted, and rotated in order to wash down any particles adhering to the inside of the flask.

Alter the last compound had been added and dissolved, $2 \mathrm{ml}$ of bis(2-ethylhexyl)amine was added. The lot solution in the flask was now poured in to the small beaker, and back and forth, until all traces of solid in the beaker had dissolved. After returning the solution to the flask, the beaker was washed with six 15-ml portions of lubricating oil, and these rinsings were all transferred to the flask. The oil solution was now allowed to cool to room temperature, and cool lubricating oil was added to the flask until the weight of the solution was $100 \pm 0.5 \mathrm{~g}$. The solution was reheated to $85^{\circ} \mathrm{C}$, allowed to cool to room temperature, transferred to a bottle, and tightly stoppered.

A precise determination of the maximum concentration attainable for each element of interest, either individually in oil plus solubilizers, or as a mixture of the standard compounds in oil plus solubilizers, has not been made. However, solutions having concentrations much higher than those given have been prepared and found to be stable. All solutions prepared from the standard compounds (according to the directions given) have, up to this time, shown no signs of deterioration on keeping.

The authors express their appreciation to all persons and firms who co-operated on this project. They are especially indebted to W. T. Gunn, Director of the Division of Refining, American Petroleum Institute, and to the following members of the Project Advisory Committee: C. M. Gambrill, Ethyl Corporation, Chailman; R. O. Clark, Gulf Research and Development Company; G. H. Patterson, E. I. du Pont de Nemours and Company, Inc.; E. D. Peters, Shell Development Company; and E. B. Tucker, Standard Oil Company (Indiana). They also thank the following nembers of the staff of the National Bureau of Standards who collaborated on the work and made many helpful suggestions: H. A. Bright ${ }^{8}$ and E. Wichers. Technical assistance was rendered by A. D. Kuchta (summer student, 1957 and 1958). Spectrographic analyses were performed by E. K. Hubbard and R. Alvarez of the Spectrochemistry Section. Chemical analyses were made by B. B. Bendigo and L. A. Machlan of the Standard Reference Materials Section, and the determinations of the weight-stabilities were made by B. B. Bendigo.

The following companies supplied samples of some of the materials used in this research and, in some instances, gave valuable advice: Advance Solvents \& Chemicals, Division of Carlisle Chemical Works, Inc., New Brunswick, N.J.; Carbide \& Carbon Chemicals Co., Division of Union Carbide \& Carbon Corp., Baltimore, Md., and Charleston, W. Va.; Elastomer Chemicals Dept., E. I. du Pont de Nemours \& Co., Inc., Wilmington, Del.; Ethyl Corporation, Detroit, Mich.; General Electric Co., Chemical \& Metallurgical Div. and Silicone Products Dept., Waterford, N.Y.; Gulf Research \& Development Co., Pittsburgh, Pa.; Harshaw Chemical Co., Cleveland, Ohio, and Gloucester City, N.J.; Irvington Varnish \& Insulator, Irvington, N.J.; Metal \& Thermit Corp., Rahway, N.J.; Minnesota Mining \& Mfg. Co., Newark, N.J.; Monsanto Chemical Co., Organic Chemicals Div., St. Louis, Mo.; Naftone, Inc., New York, N.Y.; Nuodex Products Co., Div. of Heyden Newport Chemical Corp., Elizabeth, N.J.; Pennsalt Chemicals Corp., Industrial Div., Pennsylvania Salt Mfg. Co., Philadelphia 2, Pa.; Quaker State Oil \& Refining Co., Oil City, Pa.; Sharples Chemical Div., Pennsylvania Salt Mfg. Co., Philadelphia 2, Pa.; Shell Development Co., Emeryville, Calif.; Shell Oil Co., Inc., Martinez, Calif.; and Standard Oil Co. of Indiana, Whiting, Ind.

\section{References}

[1] R. G. Charles, J. Inorg. \& Nuclear Chem. 6, 42 (1958).

[2] C. R. Hauser, F. W. Swamer, and J. T. Adams, Org. Reactions 8, 115 (1954).

[3] G. L. O'Connor and H. R. Nace, J. Am. Chem. Soc. 77, 1578 (1955).

[4] G. T. Morgan and H. W. Moss, J. Chem. Soc. 103, 78 (1913).

[5] C. Doree and A. C. Pepper, J. Chem. Soc. 1942, 477. [6] R. G. Charles, J. Org. Chem. 22, 677 (1957).

8 Deceased, May 22, 1961. 



\section{U.S. DEPARTMENT OF COMMERCE \\ Luther H. Hodges, Secretary \\ NATIONAL BUREAU OF STANDARDS \\ A. V. Astin, Director}

\section{THE NATIONAL BUREAU OF STANDARDS}

The scope of activities of the National Bureau of Standards at its major laboratories in Washington, D.C., and Boulder, Colo., is suggested in the following listing of the divisions and sections engaged in technical work. In general, each section carries out specialized research, development, and engineering in the field indicated by its title. A brief description of the activities, and of the resultant publications, appears on the inside of the front cover.

\section{WASHINGTON, D.C.}

Electricity. Resistance and Reactance. Electrochemistry. Electrical Instruments. Magnetic Measurements. Dielectrics. High Voltage.

Metrology. Photometry and Colorimetry. Refractometry. Photographic Research. Length. Engineering Metrology. Mass and Scale. Volumetry and Densimetry.

Heat. Temperature Physics. Heat Measurements. Cryogenic Physics. Equation of State. Statistical Physics. Radiation Physics. X-ray. Radioactivity. Radiation Theory. High Energy Radiation. Radiological Equipment. Nucleonic Instrumentation. Neutron Physics.

Analytical and Inorganic Chemistry. Pure Substances. Spectrochemistry. Solution Chemistry. Standard Reference Materials. Applied Analytical Research. Crystal Chemistry.

Mechanics. Sound. Pressure and Vacuum. Fluid Mechanics. Engineering Mechanics. Rheology. Combustion Controls.

Polymers. Macromolecules: Synthesis and Structure. Polymer Chemistry. Polymer Physics. Polymer Characterization. Polymer Evaluation and Testing. Applied Polymer Standards and Research. Dental Research.

Metallurgy. Engineering Metallurgy. Microscopy and Diffraction. Metal Reactions. Metal Physics. Electrolysis and Metal Deposition.

Inorganic Solids. Engineering Ceramics. Glass. Solid State Chemistry. Crystal Growth. Physical Properties. Crystallography.

Building Research. Structural Engineering. Fire Research. Mechanical Systems. Organic Building Materials. Codes and Safety Standards. Heat Transfer. Inorganic Building Materials. Metallic Building Materials.

Applied Mathematics. Numerical Analysis. Computation. Statistical Engineering. Mathematical Physics. Operations Research.

Data Processing Systems. Components and Techniques. Computer Technology. Measurements Automation. Engineering Applications. Systems Analysis.

Atomic Physics. Spectroscopy. Infrared Spectroscopy. Solid State Physics. Electon Physics. Atomic Physics. Instrumentation. Engineering Electronics. Electron Devices. Electronic Instrumentation. Mechanical Instruments. Basic Instrumentation.

Physical Chemistry. Thermochemistry. Surface Chemistry. Organic Chemistry. Molecular Spectroscopy. Molecular Kinetics. Mass Spectrometry.

Office of Weights and Measures.

\section{BOULDER, COLO.}

Cryogenic Engineering Laboratory. Cryogenic Equipment. Cryogenic Processes. Properties of Materials. Cryogenic Technical Services.

\section{CENTRAL RADIO PROPAGaTION LABORATORY}

Ionosphere Research and Propagation. Low Frequency and Very Low Frequency Research. Ionosphere Research. Prediction Services. Sun-Earth Relationships. Field Engineering. Radio Warning Services. Vertical Soundings Research.

Radio Propagation Engineering. Data Reduction Instrumentation. Radio Noise. Tropospheric Measurements. Tropospheric Analysis. Propagation-Terrain Effects. Radio-Meteorology. Lower Atmosphere Physics.

Radio Systems. Applied Electromagnetic Theory. High Frequency and Very High Frequency Research. Modulation Research. Antenna Research. Navigation Systems.

Upper Atmosphere and Space Physics. Upper Atmosphere and Plasma Physics. Ionosphere and Exosphere Scatter. Airglow and Aurora. Ionospheric Radio Astronomy.

\section{RADIO STANDARDS LABORATORY}

Radio Physics. Radio Broadcast Service. Radio and Microwave Materials. Atomic Frequency and Time-Interval Standards. Millimeter-Wave Research.

Circuit Standards. High Frequency Electrical Standards. Microwave Circuit Standards. Electronic Calibration Center. 
